\title{
Neonatal Noninvasive Ventilation Techniques: Do We Really Need to Intubate?
}

\author{
Robert M DiBlasi RRT-NPS FAARC
}

\author{
Introduction \\ Proposed Benefits of Noninvasive Ventilation \\ Noninvasive Ventilation Modes in Neonates \\ Nasal Intermittent Mandatory Ventilation \\ Nasal Neurally Adjusted Ventilatory Assist \\ Sigh Positive Airway Pressure \\ Nasal High-Frequency Ventilation \\ Summary
}

\begin{abstract}
The current trend for supporting neonates with respiratory distress syndrome is nasal continuous positive airway pressure (CPAP). Nearly half of all neonates who are supported with CPAP will still develop respiratory failure that requires potentially injurious endotracheal intubation and invasive ventilation. Thus, the role of any neonatal clinician is to minimize invasive ventilation whenever possible, to avoid the multitude of complications that can arise when using this form of therapy. Noninvasive ventilation (NIV) is a form of respiratory assistance that provides greater respiratory support than does CPAP and may prevent intubation in a larger fraction of neonates who would otherwise fail CPAP. With the inception of nasal airway interfaces, clinicians have ushered in many different forms of NIV in neonates, often with very little experimental data to guide management. This review will explore in detail all of the different forms of neonatal NIV that are currently focused within an area of intense clinical investigation. Key words: nasal ventilation; infant mechanical ventilation; neonatal intensive care; noninvasive intermittent positive pressure ventilation; nasal continuous positive airway pressure. [Respir Care 2011;56(9):1273-1294. (O 2011 Daedalus Enterprises]
\end{abstract}

\section{Introduction}

The lungs of premature neonates lack structural development, ability to produce surfactant, and surface area for

Mr DiBlasi is affiliated with the Center for Developmental Therapeutics, Seattle Children's Research Institute, and with the Department of Respiratory Care, Seattle Children's Hospital and Research Institute, Seattle, Washington.

Mr DiBlasi presented a version of this paper at the 47th RESPIRATORY CARE Journal Conference, "Neonatal and Pediatric Respiratory Care: What Does the Future Hold?" held November 5-7, 2010, in Scottsdale, Arizona.

Mr DiBlasi has disclosed relationships with Monaghan Medical and gas exchange to occur. The problem is further complicated by apnea and the infant's inability to maintain the high work of breathing (WOB) necessary to overcome the op-

GE Healthcare. Seattle Children's Research Institute has submitted a patent application to the World Intellectual Property Organization (PCT/ US2009/039957) concerning one of the devices mentioned in this paper, and Mr DiBlasi is listed as an inventor on the application and could benefit from the invention.

Correspondence: Robert M DiBlasi RRT-NPS FAARC, Seattle Children's Research Institute - Respiratory Care, Center for Developmental Therapeutics, 1900 Ninth Avenue, Seattle WA 98101. E-mail: robert. diblasi@seattlechildrens.org.

DOI: $10.4187 /$ respcare. 01376 
posing forces that resist lung inflation during spontaneous breathing. As such, severe respiratory failure is prevalent in premature neonates with the respiratory distress syndrome (RDS). Endotracheal intubation and mechanical ventilation, or invasive ventilation has been the prevailing intervention for supporting neonates with RDS over the last 40 years. This practice has probably accounted for some of the notable reductions in infant mortality prior to the development of artificial surfactant and the widespread use of antenatal corticosteroids. ${ }^{1}$ However, even short-term invasive ventilation in animal models of respiratory distress has been associated with lung inflammation and injury, ${ }^{2}$ reduced efficacy of endogenous surfactant,${ }^{3}$ and arrest of alveolar growth and development. ${ }^{4-6}$ Ventilatorinduced lung injury (VILI) is characterized by excessive tidal volume $\left(\mathrm{V}_{\mathrm{T}}\right)$ delivery (volutrauma), ${ }^{7}$ shear injury related to repetitive cycling of distal airways at suboptimal lung volumes (atelectrauma), ${ }^{8}$ and the consequent release of biochemical substances that instigate pulmonary inflammation (biotrauma). ${ }^{9}$ VILI has been implicated as a major factor predisposing neonates to chronic lung disease or bronchopulmonary dysplasia (BPD). ${ }^{10,11}$ Interpreted in a literal sense, the term "VILI" underscores the potentially deleterious effects of other confounding factors within the ventilator system: specifically, the endotracheal tube (ETT).

"Endotrauma is the name given to injury to the airways and lungs from the disruption of homoeostasis that occurs during, and sometimes after, artificial ventilation through an ETT." 12 Although it is difficult to decouple and evaluate the injurious effects related to the ETT from those of the ventilator, the ETT is probably a major factor adding to causal respiratory failure and injury during invasive ventilation. Endotracheal intubation is a traumatic and painful procedure that requires sedation and can be associated with hemodynamic instabilities, airway emergencies, acute airway injury, colonization of the trachea, reduced ciliary movement, secretions, high resistance to air flow, and increased WOB. ${ }^{13}$ The ETT bypasses the glottis and hinders the neonate's adaptive mechanism (grunting ${ }^{14}$ ) for preserving the end-expiratory lung volume. The ETT also provides a direct route into the lower, sterile airway, which increases the risk of ventilator-associated pneumonia and sepsis. ${ }^{15}$

Nasal continuous positive airway pressure (CPAP) is an alternative to invasive ventilation that does not require an ETT and permits spontaneous breathing during continuous pressure applied with prongs in the nares. CPAP improves gas exchange, increases functional residual capacity, stabilizes the chest wall, enhances surfactant production, reduces WOB, and reduces the need for intubation and surfactant replacement therapy. ${ }^{16} \mathrm{~A}$ recent large multicenter randomized controlled trial (RCT) ${ }^{17}$ found that premature neonates supported initially with CPAP in the delivery room and given surfactant only for respiratory failure had less need for invasive ventilation and greater survival without high-frequency oscillatory ventilation (HFOV) or conventional ventilation at 7 days than did neonates assigned to intubation and early surfactant treatment.

CPAP has redefined the care of premature neonates but does not sufficiently off-load the burden of high WOB, nor is CPAP capable of providing effective alveolar ventilation for neonates whose condition worsens. As such, approximately $50-67 \%$ of very-low-birth-weight premature neonates supported initially with CPAP develop severe respiratory failure requiring intubation and invasive ventilation. ${ }^{17,18}$ Approximately $25-38 \%$ of infants fail CPAP following surfactant administration, resulting in re-intubation and invasive ventilation. ${ }^{19,20}$

Noninvasive ventilation (NIV) is a form of respiratory assistance that provides a greater level of respiratory support than does CPAP and may prevent intubation in a larger fraction of neonates who would otherwise fail CPAP. In addition to the CPAP effect of the ventilator, the patient's spontaneous breaths are assisted by patient-triggered (synchronized) or machine-triggered, time-cycled inflations during NIV. NIV has been used successfully in adult and pediatric patients, with oronasal mask and with nasal mask. With advances in ventilator technology and nasal interfaces, clinicians have begun implementing offlabel NIV in neonates, often with very little experimental clinical data to guide therapy. The most commonly used NIV modes are intermittent mandatory ventilation (IMV), neurally adjusted ventilatory assist, sigh positive airway pressure, and high-frequency ventilation. This paper reviews these NIV modes, management strategies, and the available evidence related to these interventions.

\section{Proposed Benefits of Noninvasive Ventilation}

Short-term application of NIV in neonates is not a new concept in the neonatal respiratory care community. In fact, manual resuscitators affixed with oronasal masks and PEEP valves are commonly used to assist neonates with insufficient respiratory efforts and respiratory failure. The long-term use of automated NIV in neonates was first reported in 1952 by Donald and Lord ${ }^{21}$ in a paper entitled, "Augmented Respiration: Studies in Atelectasis Neonatorum," nearly 2 decades prior to the initial description of neonatal CPAP by Gregory et al. ${ }^{22}$ Donald and Lord "amplified spontaneous breathing efforts" in neonates with a setup that included a rubber face mask and a spirometer with a spring-loaded one-way valve that collected and measured exhaled gas. Based on changes in the measured exhaled minute volume $\left(\dot{\mathrm{V}}_{\mathrm{E}}\right)$, different positive and negative pressures could be applied to the chest wall of the neonate, enclosed in a sealed plethysmograph. Further, the patient could synchronize all of his or her spontaneous respiratory efforts with the applied pressure by deflecting a light beam 
from an electrical cell to an adjacent light mirror during inhalation, which triggered the machine. Over the next few decades many negative-pressure ventilators incorporated into isolettes were tried, with less than promising outcomes. ${ }^{23}$

Following many failed attempts at providing invasive ventilation with adult-specific ventilators in neonates, Llewelyn et $\mathrm{al}^{24}$ described the often unforeseen complications arising from prolonged endotracheal intubation in 1970:

It has become evident that the advantages of such a technique must be weighed against its complications. Tube displacement and blockage are a constant hazard. Laryngeal edema and loss of ciliated tracheal mucosa with ulceration are common necropsy findings after prolonged intubation, and these predispose to permanent laryngeal and tracheal damage. Infection is readily established in these infants, doubtless due in part to the repeated introduction of suction catheters.

In an effort to avoid intubation but to retain the clinical benefits of positive-pressure ventilation, Llewelyn et $\mathrm{al}^{24}$ and Helmrath et al ${ }^{25}$ reported separately in 1970 their initial experiences with ventilation applied with a firmly attached oronasal mask, using pressure-cycled intermittent positive-pressure devices and pediatric volume-cycled ventilators. NIV via face mask resulted in better gas exchange, ability to wean oxygen, less lung infection, and less need for invasive ventilation than did standard treatment with oxygen therapy. ${ }^{24}$ In 1976, Pape et al ${ }^{26}$ described severe head molding from the straps used to secure the face mask during NIV, especially in preterm neonates $<1,500 \mathrm{~g}$. Although the use of mask NIV reduced the neonatal mortality rate from $75 \%$ to $45 \%$ in their intensive care unit, this practice was associated with an alarmingly higher rate of cerebellar hemorrhage at autopsy than in neonates supported with invasive ventilation via nasal ETT. Attempts were made during this time to develop new techniques for securing the face mask that would decrease the risk of head molding and consequent neurologic complications during NIV. ${ }^{27}$

Following the initial description of nasal prongs by Kattiwinkel et $\mathrm{al}^{28}$ and Caliumi-Pellegrini et $\mathrm{al}^{29}$ to deliver CPAP, Moretti et al ${ }^{30}$ described the first successful application of NIV with bi-nasal prongs in preterm neonates with respiratory failure and apnea. The widespread use of NIV was temporarily hampered following the publication of a paper by Garland et al, ${ }^{31}$ who found that neonates ventilated with either oronasal mask or nasal prongs were 30 times more likely to develop gastrointestinal perforations than were neonates ventilated with ETT. Following the advent of neonatal-specific, patient-triggered ventilators, Friedlich et al ${ }^{32}$ introduced patient-triggered (or syn-

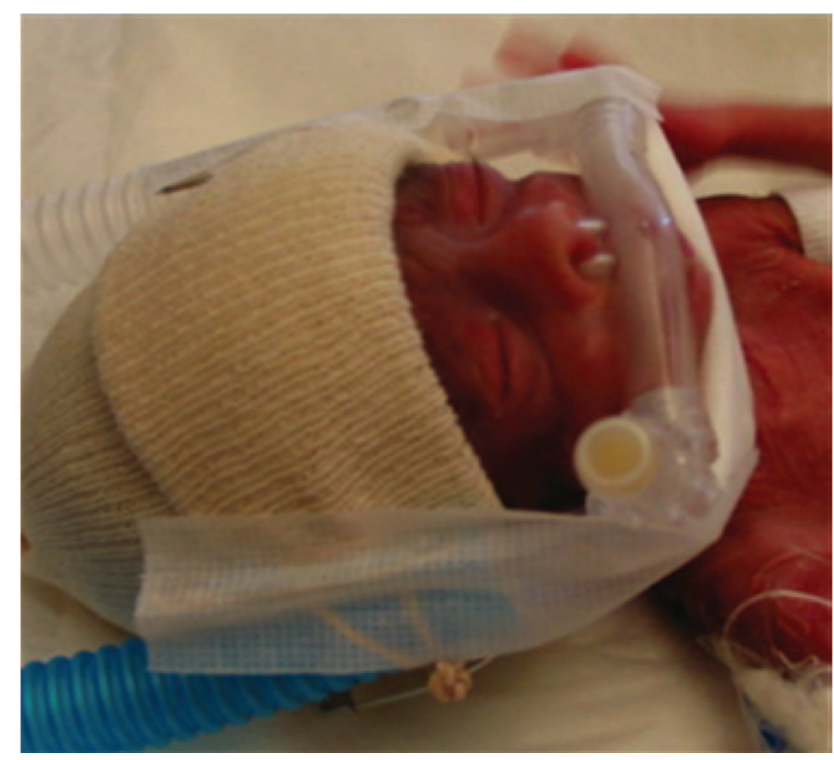

Fig. 1. A premature neonate with bi-nasal short prongs and an improvised chin strap secured with cloth and tape to prevent oral air leakage. (Courtesy of Rose DeKlerk, Vermont Oxford Network.)

chronized) nasal IMV in neonates, and clinicians became interested in using NIV again.

As mentioned previously, the goals of NIV are to assist weak or ineffective spontaneous breathing, avoid endotrauma, and noninvasively support a larger fraction of premature neonates who would otherwise fail CPAP or remain intubated and mechanically ventilated. In theory, minimizing invasive ventilation may reduce BPD and other neonatal complications. In addition to supporting premature neonates with RDS, NIV has been used successfully in neonates with other forms of respiratory failure, including congenital pneumonia, meconium aspiration syndrome, transient tachypnea of the newborn, and neuromuscular disorders. Based on the successes of NIV in neonates, interest in using NIV in larger infants and toddlers with respiratory distress has increased, but these approaches have been hampered by the lack of available nasal airway interfaces designed for this population.

Neonatal nasal airway interfaces and fixation techniques during NIV are similar to those used for CPAP. ${ }^{16} \mathrm{Bi}$-nasal short-prongs (Fig. 1) are the most commonly used nasal interface because they impose lower resistance and, hence, less WOB than do ETTs. ${ }^{33}$ Obviating the ETT during mechanical ventilation may avoid many of the complications associated with endotrauma, but may not avoid all of the complications associated with VILI. The approach and settings used to manage neonates during NIV are similar to invasive ventilation, so VILI is still a concern during NIV. However, during NIV, a natural lung-protective pressure-relief valve exists via leaky nasal airway interfaces and the oropharynx, which may prevent excessive pressure transmission to the distal airways. ${ }^{13}$ As such, some clini- 
cians still prefer nasopharyngeal ETTs, placed $2-3 \mathrm{~cm}$ into a single nare during NIV, because the contralateral nare acts as an additional pressure pressure-relief valve that can further vent excessive pressure to the atmosphere more readily than a tracheal tube or bi-nasal prongs. A potential limitation of excessive airway leak during NIV is that sufficient pressure may not be delivered to maintain lung inflation.

Perhaps the greatest known benefit of NIV is that it maintains a higher mean airway pressure than CPAP. This provides a greater ability to recruit collapsed alveoli, maintain end-expiratory lung volume, and improve oxygenation. Providing inflations above CPAP pressure augments $\mathrm{V}_{\mathrm{T}}$ and can provide sigh breaths, which may also improve gas exchange and recruit areas of microatelectasis or airway collapse. Additionally, NIV preserves the neonate's natural ability to augment lung volume, because the glottis is unimpeded by an ETT. Neonates who are apneic may not always receive sufficient support from NIV, but NIV should reduce the magnitude and severity of apneas.

In a recent survey, Owen et $\mathrm{al}^{34}$ found that $45 \%$ of all neonatal intensive care units (NICUs) in England used some form of NIV to support neonates. How many hospitals in the United States are currently using nasal IMV is unclear, but the results of some compelling new clinical research suggest that this number is likely to be large and growing. The proposed physiologic benefits of NIV as well as management strategies and clinical data, as they relate to the different forms of NIV being used to support neonates with lung disease, are discussed below.

\section{Noninvasive Ventilation Modes in Neonates}

\section{Nasal Intermittent Mandatory Ventilation}

The most widely used and studied form of NIV in neonates is nasal IMV. Nasal IMV is a useful intermediate strategy for neonates weaning from mechanical ventilation or who cannot be supported by CPAP alone. Nasal IMV embraces spontaneous breathing, with a conventional neonatal ventilator equipped with bi-nasal prongs or a single nasopharyngeal ETT. In some settings, clinicians have also adapted small nasal masks to be used during nasal IMV. The most commonly used mode for nasal IMV is timecycled, pressure control ventilation, with or without a preset constant flow. Similar to CPAP, unassisted spontaneous breathing occurs at a pre-set PEEP level, but mandatory pressure control breaths are either patient-triggered (synchronized) or machine-triggered (non-synchronized).

Although pressure support ventilation (PSV) is commonly used during adult NIV, it is not used to support spontaneous breaths during nasal IMV or as a singular mode during NIV, because it cannot flow-cycle breaths in the presence of a large airway leak. I will only briefly review the 2 studies that have evaluated the noninvasive application of PSV in infants. In one study, ${ }^{35}$ a prototype nasal mask was used to apply PSV to larger infants (approximately $4 \mathrm{~kg}$ ) with respiratory failure. The infants supported with PSV had lower respiratory rates $(P<.001)$ and indices of WOB $(P<.01)$ than did spontaneously breathing infants given no support. ${ }^{35}$

The only randomized crossover study in neonates that has evaluated nasal PSV used the IV-200 SAVI ventilator (Sechrist Industries, Anaheim, California) and short binasal prongs. ${ }^{36}$ Nasal PSV was delivered with the SAVI mode, which is different from conventional PSV. Rather than using a flow signal to trigger and cycle the breath, SAVI triggers and cycles the inspiration based on signals from respiratory inductance plethysmography bands placed on the chest. Nasal PSV did not measurably augment alveolar ventilation, but did provide lower indices of WOB and respiratory effort. The SAVI ventilator is no longer available, and it is unclear whether this form of NIV will appear in future ventilators. Clinical data supportive of the efficacy of nasal PSV are lacking, and conventional flowtriggered, flow-cycled PSV is unlikely to be effective in this population, especially if large leaks are present. Thus, it appears safer and easier to implement IMV, instead of PSV, to assure proper breath-termination during NIV.

Triggering Options. The noninvasive application of machine-triggered IMV involves time-triggered mandatory breaths that may or may not be in phase with the neonate's spontaneous inspiratory or expiratory efforts. Clinicians have often speculated that positive pressure delivered during the expiratory phase may increase the airway pressure beyond the set inspiratory pressure; elicit active expiratory efforts; and increase WOB, the risk of air leak, and gastric insufflation. Owen et al $^{37}$ evaluated the range and variability of delivered pressure in preterm neonates receiving machine-triggered IMV via bi-nasal short prongs, fitted with chin-strap attachment, and found that airway pressure can vary considerably from the set pressure: approximately $5 \mathrm{~cm} \mathrm{H}_{2} \mathrm{O}$ less than the pre-set inspiratory pressure $37 \%$ and $83 \%$ of the time when inspiratory pressure was set at $20 \mathrm{~cm} \mathrm{H}_{2} \mathrm{O}$ and $25 \mathrm{~cm} \mathrm{H}_{2} \mathrm{O}$, respectively. With nasal IMV, only actively moving patients exceeded the set inspiratory pressure $13 \%$ and $6 \%$ of the time, when inspiratory pressure was set at $20 \mathrm{~cm} \mathrm{H}_{2} \mathrm{O}$ and $25 \mathrm{~cm} \mathrm{H}_{2} \mathrm{O}$, respectively. And $63 \%$ of mechanical inflations were delivered during spontaneous exhalation, but airway pressure did not vary according to whether ventilator inflation timing was during spontaneous inspiration or expiration. Many of the current ventilators being used for nasal IMV will automatically limit inspiratory pressure to $2 \mathrm{~cm} \mathrm{H}_{2} \mathrm{O}$ greater than the set inspiratory pressure. Nonetheless, adjusting the highpressure limit is important, to assure lung protection and reduce the risk of gastric insufflation during nasal IMV. 
Despite not being able to trigger the ventilator, several of the clinical benefits of patient-triggered nasal IMV can still be appreciated with machine-triggered nasal IMV. Patients supported by machine-triggered nasal IMV can usually easily adapt to the ventilator within a short period, especially if the ventilator rate is set to at least $50 \%$ of their total respiratory rate. ${ }^{38}$ The ability to adapt to the inflations is most likely related to stimulation of the Hering-Breuer reflex or mediated by a reflex activated by a jet of gas flow into the nasal passages. ${ }^{39}$ Older-generation ventilators may have been better suited for this purpose than are current-generation ventilators, which incorporate flow-triggering options and numerous disconnect alarms. Clinicians have circumvented auto-triggering by disabling the set flow and pressure trigger levels; however, many ventilators have disconnect alarms that cannot be silenced in the face of large leaks. There have been anecdotal reports of clinicians bleeding gas into the ventilator's exhalation limb from an auxiliary flow meter to quiet the disconnect alarms, but that practice is not recommended, as it may pose safety risks. Ventilator manufacturers are now releasing FDA-approved modes of neonatal noninvasive IMV, but many of the devices offer only machine-triggered nasal IMV.

Although patient-triggered IMV has been implemented with proximal hot-wire flow sensors ${ }^{38}$ and pressure sensors placed at the nares, appropriate triggering may be difficult, if not impossible, because of the large positional leaks that can develop between the patient's airway and the nasal interface..$^{40}$ This often results in auto-triggering and/or failed triggering. Additionally, the risks posed by the added weight and dead space from a proximal flow sensor may outweigh the clinical benefits of patient-triggered breaths during nasal IMV. Newer-generation neonatal ventilators incorporate flow-triggering and leakcompensation algorithms that can automatically adjust the trigger level based on large airway leaks. Anecdotal reports suggest that these triggering options work well in premature neonates during nasal IMV, but no data have been published on the trigger performance of these modes during neonatal nasal IMV.

Traditionally, the most commonly used device for patient-triggered nasal IMV has been the Infrasonics Infant Star ventilator (Mallinckrodt, St Louis, Missouri) with the StarSynch module, which incorporates an abdominal pneumatic (Graseby) capsule, attached below the xiphoid process, that detects diaphragm descent, so triggering is independent of oral or nasal leak. The Infant Star ventilator is no longer being supported by the manufacturer, and machine-triggered nasal IMV breath types are being used with apparent success. With the demise of the Infant Star ventilator, clinicians have tried to modify other ventilators to provide patient-triggered nasal IMV with Graseby capsules and respiratory impedance bands.
In theory, patient-triggered nasal IMV is preferred because the inflations are timed with the respiratory effort, and when the glottis is open, the inflations are more likely to be transmitted effectively to the lungs. Patient-triggered nasal IMV may offer several other clinical advantages over machine-triggered IMV for neonates; however, the results of a recent Cochrane meta-analysis concluded that invasive patient-triggered IMV (synchronized IMV) in neonates resulted in shorter duration of ventilation and weaning than did invasive machine-triggered ventilation. ${ }^{41}$ It is interesting to note that there were no differences in air leak, BPD, or any other chronic morbidities between neonates supported by these 2 forms of triggered ventilation. However, there have been no studies designed to assess differences in long-term outcomes related to the available noninvasive IMV triggering options.

Chang et $\mathrm{al}^{42}$ compared short-term (one-hour) physiologic effects of machine-triggered nasal IMV (20 and 40 breaths/min) and patient-triggered nasal IMV (20 and 40 breaths/min) with CPAP in 16 clinically stable preterm infants. Overall, there were no differences in $V_{T}, \dot{V}_{E}$, gas exchange, chest-wall distortion, apnea, hypoxemia spells, or abdominal girth between the different forms of noninvasive support. Patient-triggered nasal IMV provided lower breathing effort and better infant/ventilator interaction than did machine-triggered IMV or CPAP. These findings were more striking at 40 breaths/min than at 20 breaths/min during nasal IMV. Nonetheless, these differences in ventilator interaction did not appear to affect patient comfort or any other measured variable. Further, the low inspiratory pressure setting $\left(10 \mathrm{~cm} \mathrm{H}_{2} \mathrm{O}\right)$ was much lower than is typically used in the clinical setting, and may not have resulted in sufficient pressure transmission the lungs, especially if a leak was present. These findings in part are different from those reported by investigators who supported sicker neonates and with higher inspiratory pressures than those reported in the Chang et al study. The results from the latter studies will be discussed in the next section.

Based on the findings from nearly 2 decades of research evaluating outcomes in patient-triggered ventilation during invasive ventilation, a large clinical trial to compare long-term outcomes in premature neonates supported by machine-triggered or patient-triggered nasal IMV is unlikely to be conducted. Such studies would require a large number of patients and a tremendous amount of time and funding. Anecdotal reports and the limited clinical data available suggest that new modes or ventilator platforms that offer patient-triggered nasal IMV may be preferable, but may not be absolutely necessary at this time.

Physiologic Effects. The physiologic mechanisms by which nasal IMV works in preterm neonates are not fully understood, and whether nasal IMV is more effective than 


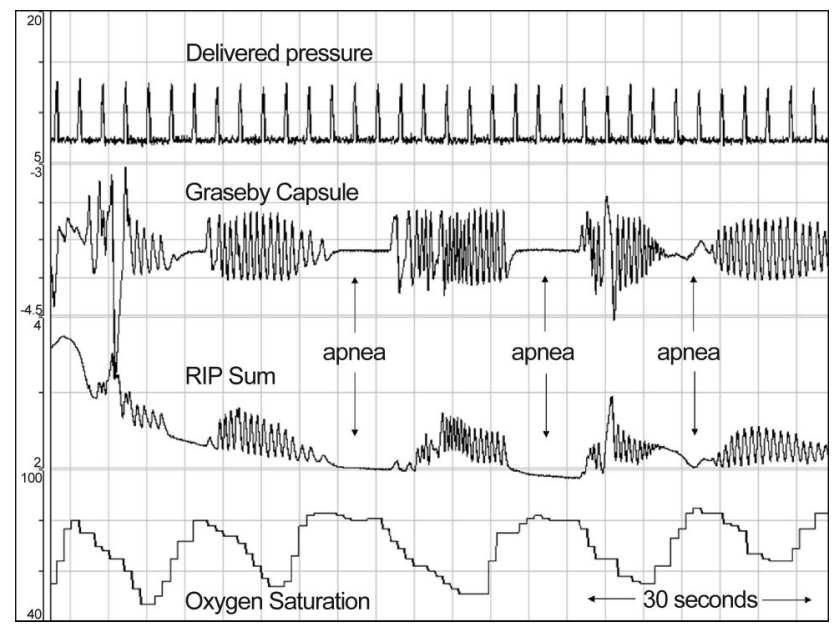

Fig. 2. A 2-min recording showing periodic breathing, stable delivered pressure, and fluctuating oxygen saturation in a premature neonate supported by nasal intermittent mandatory ventilation (IMV) with a set peak inspiratory pressure of $20 \mathrm{~cm} \mathrm{H}_{2} \mathrm{O}$ and a respiratory rate of 20 inflations per minute. The loss of end-expiratory lung volume, denoted by the decrease in the respiratory impedance pneumography (RIP) sum trace at the onset of apnea suggests central apnea with an open glottis. Based on the absence of chest-wall excursions during apnea, nasal IMV did not sufficiently augment tidal volume, despite the use of a chin strap. (Adapted from Reference 37, with permission.)

CPAP or invasive ventilation is a topic of intense clinical research. In premature neonates, compared to CPAP, patient-triggered nasal IMV has been associated with greater $\mathrm{V}_{\mathrm{T}}$ and $\dot{\mathrm{V}}_{\mathrm{E}}$, and reduced thoracoabdominal asynchrony (chest-wall stabilization), ${ }^{43}$ respiratory rate, gas exchange, ${ }^{44}$ and WOB, ${ }^{38,45}$ but nasal IMV may cause more discomfort due to the high flow rate, local nasal irritation, and asynchrony. In premature neonates, Kugelman et al ${ }^{46}$ found that nasal IMV was associated with higher blood pressure and discomfort score than was unassisted spontaneous breathing. However, Kulkarni et $\mathrm{al}^{47}$ found no difference in nutrition intake or weight gain between neonates supported by CPAP versus IMV.

Nasal IMV is more effective than is CPAP in reducing the incidence of apnea in preterm neonates. ${ }^{48,49}$ However, nasal IMV is more likely to prevent apnea than to support a patient who is apneic. Neonates with existing apnea may not always be adequately supported by nasal IMV, because the pressure is not always transmitted to the lungs (Fig. 2), due to large airway leaks, reduced compliance, and/or airway obstruction. ${ }^{48,50}$ The physiologic mechanisms responsible for the notable reductions in central and obstructive apnea are not fully understood. Since nasal IMV provides more support than CPAP, the higher inflation and mean airway pressure improve gas exchange, which can reduce the frequency and severity of central apnea episodes. Nasal IMV also creates higher pharyngeal pressure than does nasal CPAP, and by intermittent infla- tion of the pharynx, nasal IMV can stent open the airway, activate the dilator muscles of the pharynx, and increase the respiratory drive to abort obstructive apneas. ${ }^{48}$ Additionally, higher inspiratory flow may produce a fast rise in the airway pressure so that the soft palate can be pushed against the tongue and seal the oral cavity, resulting in better breath delivery during an obstructive apnea. ${ }^{30}$ IMV augments a neonate's spontaneous respiratory effort or increases "sighing," which may be useful for recruiting and maintaining distal air spaces and preventing apnea.

In a report by Lin et al ${ }^{48}$ the chest wall excursions of neonates were monitored during machine-triggered nasal IMV and CPAP, using respiratory impedance bands. A biphasic inspiratory response was observed in infants treated with nasal IMV, indicating that the onset of a positive-pressure breath may induce sighing. A similar reflex was described by Head et al in spontaneously breathing rabbits receiving positive-pressure ventilation, and has since been called "the Head paradoxical maneuver" and is thought to arise from sensors in the lung. ${ }^{51}$

Greenough et al ${ }^{52,53}$ reported a similar phenomenon in spontaneously breathing neonates instrumented with an esophageal balloon and supported with invasive ventilation, wherein (Fig. 3) augmented spontaneous inspiratory efforts were provoked at the onset of rapid positive-pressure inflation and were prevalent in preterm neonates with reduced compliance, higher inspiratory pressure, and ventilator rate $<15$ breaths/min. They also found that neonates receiving theophylline and those following recovery from chemical paralysis had a higher incidence of this beneficial reflex. ${ }^{52,53}$

As mentioned previously, the beneficial lung-protective effects of nasal IMV have been attributed to the use of a "leaky" nasal airway interface. Only one animal study has tested the hypothesis that noninvasive IMV results in less lung injury than invasive IMV. Lampland et $\mathrm{al}^{54}$ compared differences in pathophysiologic and pathologic conditions in surfactant-deficient, lung-lavaged piglets supported by patient-triggered invasive IMV or noninvasive IMV. Animals from both groups were managed using a standardized ventilator protocol. Animals supported by noninvasive IMV had higher arterial blood gas $\mathrm{pH}(P<.001)$, lower $\mathrm{P}_{\mathrm{aCO}_{2}}(P<.05)$, and lower respiratory rate $(P<.001)$ than did piglets treated with synchronized IMV. The piglets in the invasive IMV group had a higher ratio of $\mathrm{P}_{\mathrm{aO}_{2}}$ to alveolar $\mathrm{P}_{\mathrm{O}_{2}}(P<.04)$ and more pulmonary interstitial inflammation than did noninvasive IMV treated piglets. The results from this short-term study (6 hours) demonstrate that noninvasive IMV may be less injurious to the lung and provide better ventilation with less need for support than does invasive IMV.

Complications. Many of the same complications that arise during CPAP and invasive ventilation can present 


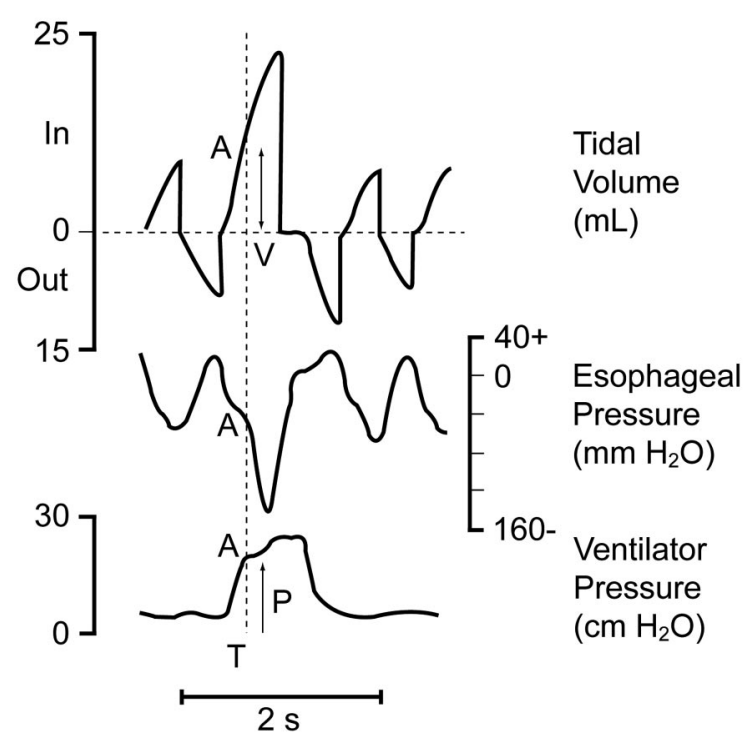

Fig. 3. Provoked augmented inspiratory response in a neonate receiving invasive ventilation. In the tidal volume trace the integrator resets to zero at zero air flow, so an upward deflection represents inspiration and a downward deflection represents expiration. In the esophageal pressure trace, downward deflections (ie, increasing negative pressure) are caused by spontaneous respiratory activity. The provoked augmented inspiration commences at point $A$, shown by the large deflection in the esophageal trace, during ventilator inflation, which is at least twice the size of that caused by spontaneous (unassisted) inspiration. At point $A$ the volume $(V)$ and the inflating pressure $(P)$ provoke the reflex. $T$ is the time from the start of the inflation to the beginning of the augmented inspiration. A similar response has been observed in neonates receiving nasal IMV. (Adapted from Reference 53, with permission.)

during nasal IMV, and can present with all forms of neonatal NIV. The most frequently reported complication is local irritation and trauma to the nasal septum, which may occur due to misalignment or improper fixation of nasal prongs. This can also result in nasal snubbing and circumferential distortion (widening) of the nares, ${ }^{16}$ especially if nasal IMV is being used for more than just a few days. Clinicians have improved the level of nasal care and are more wary of avoiding nasal airway trauma. Cannulaide (Beevers Manufacturing, McMinnville, Oregon) is a tailored hydrocolloid material with an adhesive backing that is fitted over the nose and moustache area to protect skin and prevent nasal breakdown (Fig. 4). The holes on the Cannulaide are a smaller diameter than the nare, so when prongs are placed, the Cannulaide may reduce nasal leak. Owen et $a^{55}$ evaluated the clinical effects prior to and following Cannulaide placement during neonatal nasal IMV and found that the Cannulaide increased airway pressure and resulted in a nonsignificant trend toward fewer desaturations and apneas.

Ramanathan and colleagues have reported successful use of high-flow nasal cannula as a means of avoiding

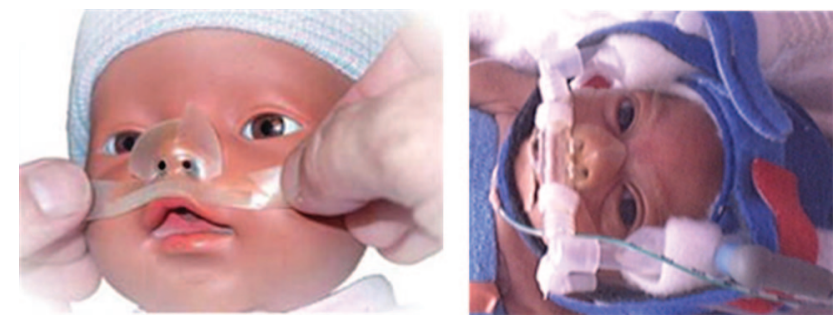

Fig. 4. Cannulaide (Beevers Manufacturing, McMinnville, Oregon) barrier device being applied to a doll (left) and in use with a premature neonate. (Courtesy of Louise Owen MD.)

complicated fixation techniques and consequent nasal injury during nasal IMV. In an observational cohort, 70 premature neonates were treated with nasal cannula IMV. ${ }^{56}$ All the neonates tolerated nasal cannula IMV, and there were no cases of nasal injury, air leaks, or gastric or eardrum perforation. The nasal cannula IMV failure rate (ie, required re-intubation) was $8 \%$. Nasal cannula IMV has also been evaluated in a realistic neonatal nasal airway/ lung model ${ }^{57}$ with infant and intermediate size high-flow nasal cannula (Fisher Paykel, Auckland, New Zealand) and a new prototype nasal cannula (RAM, NeoTech, Valencia, California) which has larger-bore tubing than a standard oxygen or high-flow nasal cannula. The intended purpose of the larger-bore tubing is to reduce resistance so that more pressure can be transmitted to the nares without adding imposed WOB during spontaneous breathing. Despite a nasal airway leak, IMV provided through these hybrid prongs resulted in acceptable pressure and volume delivered to the lung model. Compared with bi-nasal short prongs and nasal masks that are used during NIV, nasal cannula IMV represents a less cumbersome interface that may reduce complications and still provide sufficient ventilatory assistance during IMV.

Like CPAP, gastric insufflation of gases is a frequently reported risk during nasal IMV. In a recent study, anesthetized neonates had gastric insufflation at inspiratory pressures of $>15 \mathrm{~cm} \mathrm{H}_{2} \mathrm{O}$ during NIV with a manual resuscitator. ${ }^{58}$ However, these neonates were not breathing spontaneously, did not have orogastric or nasogastric tubes in place, and were ventilated with oronasal mask. Inspiratory pressures $>15 \mathrm{~cm} \mathrm{H}_{2} \mathrm{O}$ probably can be used safely and effectively with bi-nasal prongs during IMV. An orogastric tube is placed to vent insufflated gas from the stomach and decompress the gastrointestinal tract. Abdominal girth should be monitored frequently during nasal IMV to assure that the orogastric tube is working properly.

The major risk from gastric insufflation is gastrointestinal perforation and necrotizing enterocolitis, which have been frequently observed during face-mask NIV in neonates. Despite the use of an orogastric tube, Garland et $\mathrm{al}^{31}$ reported gastric perforation in a small series of neonates during IMV via bi-nasal prongs and inspiratory pressure of 
approximately $19 \mathrm{~cm} \mathrm{H}_{2} \mathrm{O}$ (range $10-30 \mathrm{~cm} \mathrm{H}_{2} \mathrm{O}$ ). Based on these findings, it was suggested that "nasal prongs should not be routinely used to ventilate critically ill neonates with respiratory failure." However, neonates in that study also had chin straps in place to avoid excessive air leak, which may have increased the risk of gastric insufflation and perforation. The next section will review all of the observed complications during clinical studies. In all of these clinical studies, nasal IMV does not place the neonate at any greater reported risk for developing any of the above-mentioned complications than does CPAP.

Clinical Data. Historically, nasal IMV has been used as a means for weaning preterm neonates with apnea from invasive ventilation to CPAP. Today nasal IMV is being implemented in premature neonates with the following strategies:

After Extubation, Following Long-Term Invasive Ventilation. Extubation following prolonged mechanical ventilation is frequently associated with post-extubation respiratory failure due to apneas, atelectasis, hypoxemia, respiratory acidosis, and apnea. ${ }^{32}$ Compared to extubation to no respiratory support, extubation to CPAP has been associated with lower incidence of respiratory failure, need for mechanical ventilation, and risk of developing BPD in preterm neonates. ${ }^{59}$ However, nearly half of these neonates fail CPAP and require re-intubation.

Nasal IMV is being used immediately following extubation or when a patient is failing CPAP. Clinicians may assess patients for IMV following administration and confirmation of adequate serum aminophylline level, and once the patient has weaned to a mandatory breath rate of 12 breaths/min, inspiratory pressure $\leq 23 \mathrm{~cm} \mathrm{H}_{2} \mathrm{O}$, PEEP $\leq 6 \mathrm{~cm} \mathrm{H}_{2} \mathrm{O}$, and $\mathrm{F}_{\mathrm{IO}_{2}} \leq 0.40 .^{32}$ Table 1 shows the study designs, devices, initial settings, and outcomes in studies where nasal IMV was used in neonates following extubation from prolonged invasive ventilation.

A Cochrane Collaboration comprehensive systematic review and meta-analysis of randomized trials of nasal IMV in preterm neonates ${ }^{60}$ included 3 studies. ${ }^{32,49,61}$ The objective of the meta-analysis was to determine whether NIV was associated with a lower extubation-failure rate, without adverse effects, in preterm infants extubated following prolonged invasive ventilation than was nasal CPAP. All 3 trials used patient-triggered nasal IMV. The meta-analysis $^{60}$ found statistically significant and clinically important reductions in the risk of meeting extubation failure criteria: typical risk ratio 0.21 (95\% CI 0.10-0.45), typical risk difference -0.32 , (95\% CI -0.45 to -0.20$)$, numberneeded-to-treat 3 (95\% CI 2-5). No gastrointestinal perforations were reported in any of the trials. The differences in the rates of chronic lung disease approached but did not reach statistical significance, favoring nasal IMV: typical risk ratio 0.73 (95\% CI $0.49-1.07)$, typical risk difference -0.15 (95\% CI -0.33 to 0.03 ).

A small retrospective study ${ }^{47}$ that was not included in the Cochrane review ${ }^{60}$ compared outcomes in premature neonates supported by CPAP and patient-triggered nasal IMV following prolonged invasive ventilation. The nasal IMV group had less supplemental oxygen requirement $(P<.02)$ and BPD $(P<.01)$ than did infants supported by CPAP, and there were no differences in complications related to either form of respiratory support. Another study, by Ryan et al, ${ }^{50}$ reported no differences in apnea, bradycardia, or transcutaneous $\mathrm{CO}_{2}$ between neonates on nasal IMV versus CPAP. However, that was a short-term study with a small number of patients and used a ventilator that provided only machine-triggered IMV.

After Extubation, Following Surfactant Replacement and Short-Term Invasive Ventilation. One of the primary reasons preterm neonates $(<34$ weeks) develop severe respiratory failure with any form of noninvasive respiratory support is that the lungs are incapable of producing and secreting sufficient quantities of mature endogenous surfactant. In recent years the practice of intubation, administering surfactant replacement (10-15 $\mathrm{min})$, and shortterm ventilation (usually $<1 \mathrm{~h}$ ), with extubation to prophylactic CPAP has become a widely applied approach for preterm neonates. A meta-analyses ${ }^{62}$ evaluated outcomes from 6 RCTs to compare early (prophylactic) surfactant administration with brief ventilation versus selective surfactant and continued mechanical ventilation in premature infants with or at risk for RDS. Intubation and early surfactant administration followed by extubation to CPAP was associated with a lower incidence of mechanical ventilation (typical risk ratio $0.67,95 \%$ CI $0.57-0.79$ ), air leak syndromes (typical risk ratio 0.52 , 95\% CI 0.28 0.96 ), and infant chronic lung disease (typical risk ratio 0.51, 95\% CI 0.26-0.99). Despite this novel approach, neonates still develop respiratory failure while receiving CPAP, which further highlights the need for intermediary forms of respiratory support as an alternative to intubation and invasive ventilation.

Table 2 shows the study designs, devices, initial settings, and outcomes in studies in which nasal IMV was used in neonates following surfactant replacement and short-term ventilation. All but one of these trials used patient-triggered nasal IMV.

Santin et al ${ }^{63}$ conducted a prospective pilot study that compared outcomes of neonates supported with early nasal IMV (immediately following surfactant and extubation) and later nasal IMV (following surfactant, continued ventilator support, and extubation). The early-nasal IMV infants had shorter duration of ventilation $(P=.001)$, less supplemental oxygen requirement $(P=.04)$, shorter stay $(P=.04)$, and less parenteral nutrition $(P=.002)$ than did 
Neonatal Noninvasive Ventilation Techniques: Do We Really Need to Intubate?

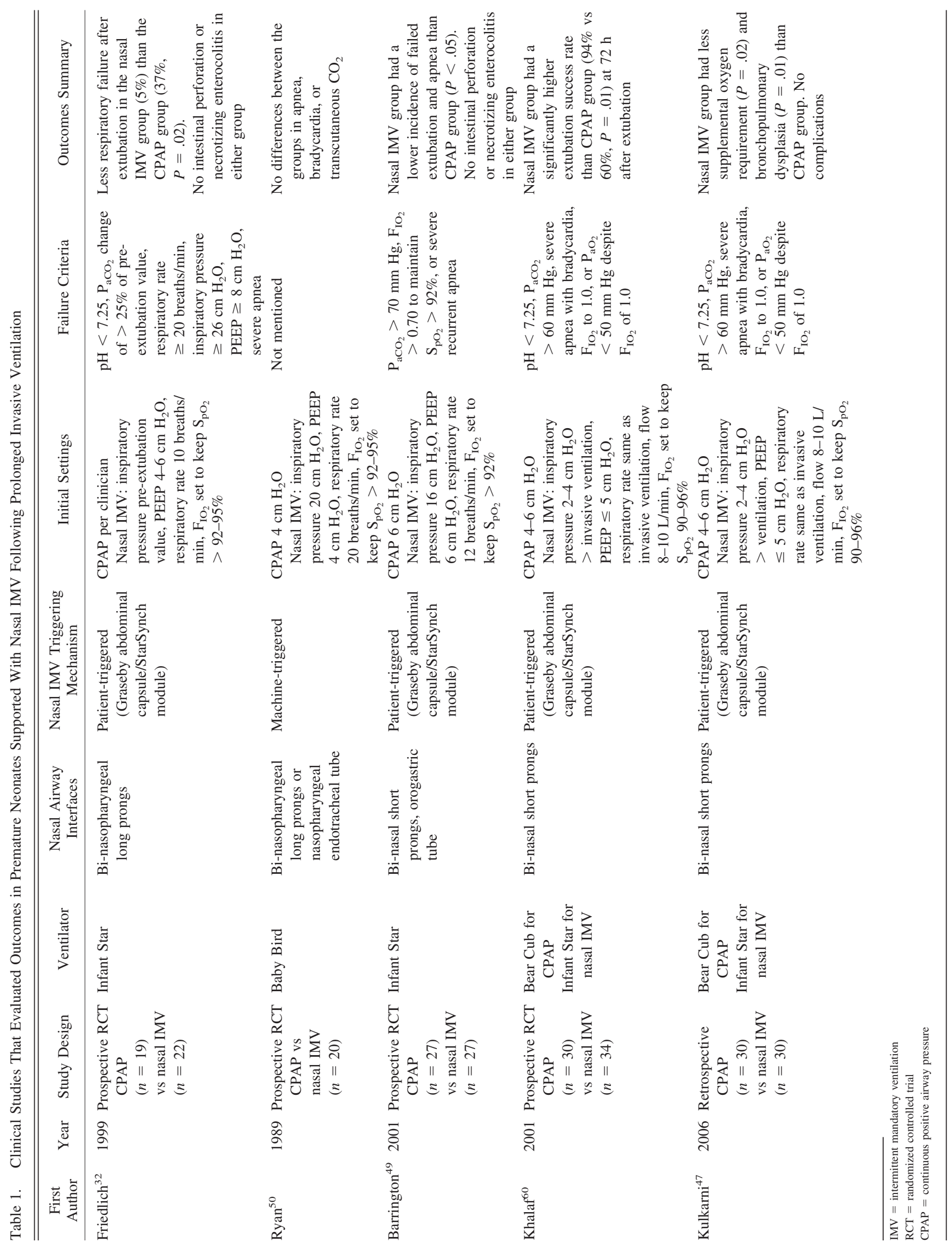


Neonatal Noninvasive Ventilation Techniques: Do We Really Need to Intubate?

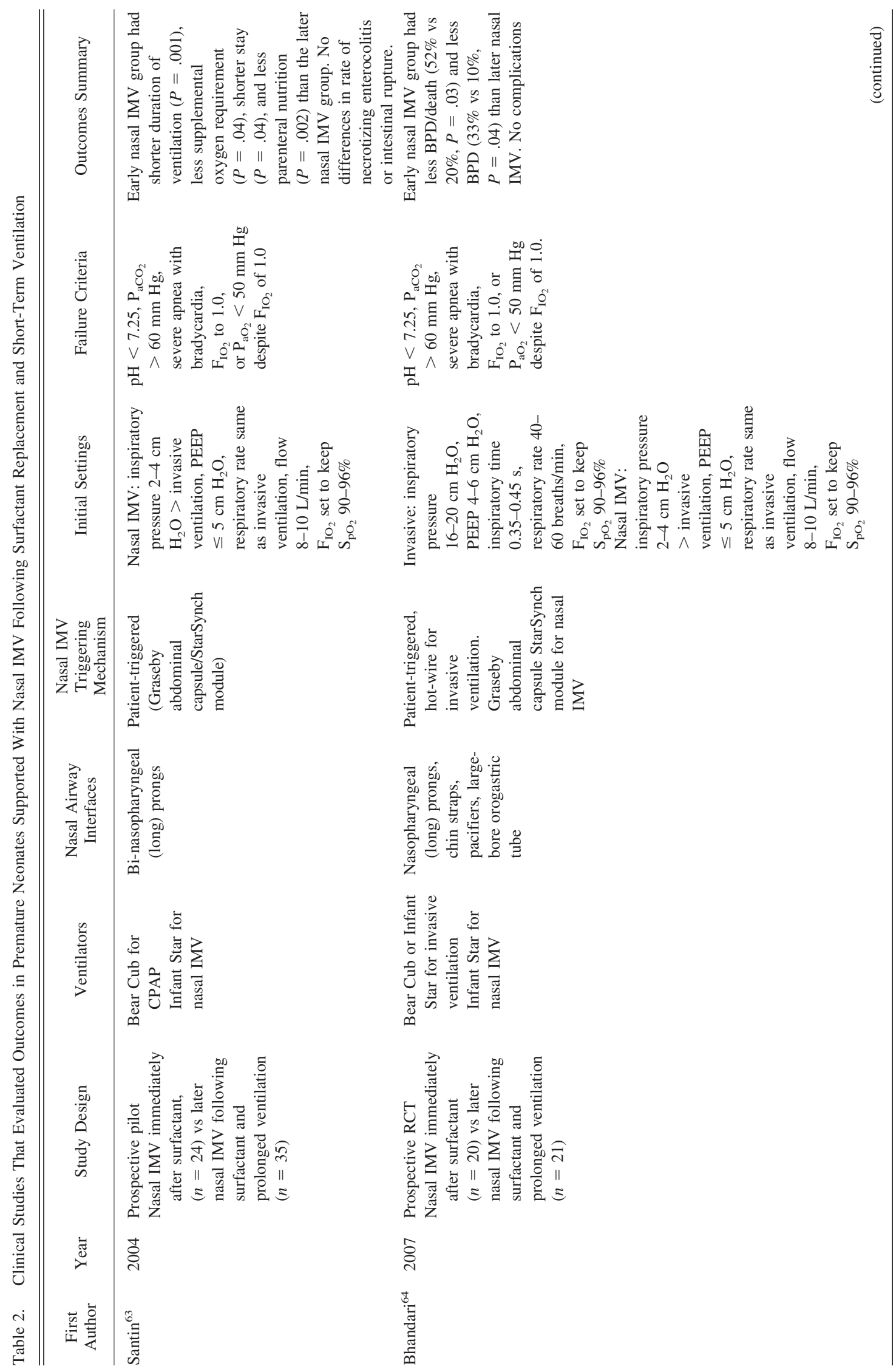




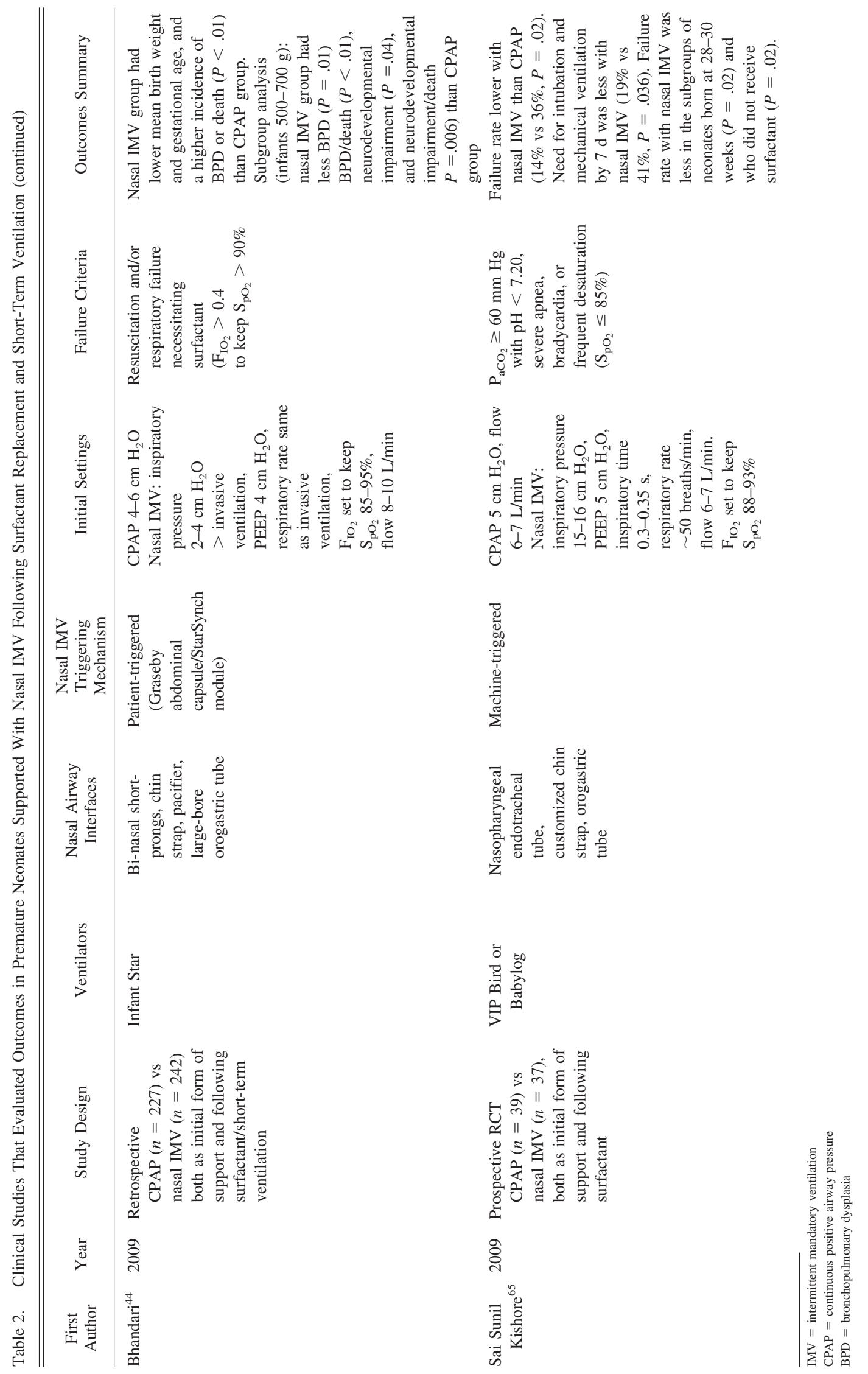


the later-nasal IMV infants. In a similar follow-up prospective randomized study by Bhandari et al, ${ }^{64}$ premature neonates supported by early nasal IMV had less BPD or death $(52 \%$ vs $20 \%, P=.03)$ and less BPD $(33 \%$ vs $10 \%$, $P=.04)$ than did the later-nasal IMV neonates.

Bhandari et $\mathrm{al}^{44}$ conducted a retrospective study of outcomes in premature neonates supported with CPAP or IMV as an initial form of support immediately following surfactant, short-term ventilation, and extubation. A small number of patients who never received any previous intubation were also enrolled. The nasal IMV group had lower mean birth weight and gestational age, and a higher incidence of BPD or death $(P<.01)$ than did the CPAP infants. However, subgroup analysis of the smallest neonates $(500-700 \mathrm{~g})$ revealed that the nasal IMV group had less BPD $(P=.01)$, combined outcome of BPD/death $(P<.01)$, neurodevelopmental impairment $(P=.04)$, and combined outcome of neurodevelopmental impairment/ death $P=.006$ ) than did the infants supported by CPAP. Additionally, $\mathrm{P}_{\mathrm{aCO}_{2}}$ was lower on days 7,21, and 28 in the nasal IMV infants $(P<.01)$.

More recently, Kishore et al ${ }^{65}$ conducted a small prospective RCT with a study design similar to that of Bhandari et al. ${ }^{44}$ The extubation failure rate was lower in the nasal IMV group (14\% vs $36 \%, P=.02$ ), and the need for intubation and mechanical ventilation by 7 days was less ( $19 \%$ vs $41 \%, P=.036$ ). The failure rate with nasal IMV was lower in the subgroup of neonates born at 28-30 weeks $(P=.02)$ who did not receive surfactant $(P=.02)$. These studies suggest clinical benefit from early IMV, compared to later nasal IMV or CPAP for the initial form of noninvasive respiratory support following surfactant administration. These data also indicate the need for a large RCT enrolling premature neonates and neonates with other lung diseases.

A common concern is that chin straps may permit delivery of excessive pressure and increase the risk of gastric insufflation and pulmonary air leaks. All but one of the studies, ${ }^{63}$ discussed above used chin straps or pacifiers to maximize pressure delivery during nasal IMV, in combination with an orogastric tube, and there were no gastrointestinal complications during IMV.

As the Initial Form of Support. A number of studies have been conducted to assess whether differences between CPAP and nasal IMV would be observed in outcomes of premature neonates when initiated prior to intubation, surfactant administration, and mechanical ventilation. The goal of this approach is to eliminate the need for any invasive ventilation. Table 3 shows the study designs, devices, initial settings, and outcomes of studies in which IMV was used as an initial form of support for neonates with clinical signs of respiratory distress and apnea.
Moretti et $\mathrm{al}^{30}$ conducted an observational study wherein 10 premature neonates with moderate apnea and one neonate with progressive respiratory failure were placed on nasal IMV for 5 days. Endotracheal intubation was never performed in any of the patients during the study period, and no evidence of BPD was observed. Lin et $\mathrm{al}^{48}$ conducted an RCT in a series of neonates with apnea, who were supported with CPAP or nasal IMV over a 4-hour period. The infants treated with nasal IMV had fewer apneas per hour than the CPAP infants $(P<.02)$.

Manzar et al $^{66}$ conducted a prospective pilot study wherein premature neonates with moderate to severe respiratory failure (defined as a respiratory rate of $>60$ breaths/min, grunting, nasal flaring, subcostal or intercostal retractions, and a positive chest radiograph) were supported with nasal IMV. Eighty-one percent of the neonates were adequately supported, without needing invasive ventilation. Bisceglia et al ${ }^{67}$ conducted an $\mathrm{RCT}$ with neonates with mild to moderate RDS, defined as $\mathrm{F}_{\mathrm{IO}_{2}}$ $<0.4$ for $\mathrm{S}_{\mathrm{pO}_{2}}$ of $90-96 \%$, and radiograph suggestive of early hyaline membrane disease (ie, ground glass appearance and air bronchograms). Neonates were randomized to CPAP or IMV. Neonates supported by nasal IMV had lower $\mathrm{P}_{\mathrm{aCO}}$, less apnea, and a shorter duration of ventilation than the CPAP group $(P<.05)$. Kugelman et $\mathrm{al}^{40}$ compared CPAP and IMV in a prospective RCT in premature neonates with respiratory distress (tachypnea, grunting, flaring of nostrils, retractions, and radiographic evidence of RDS). In the total cohort, the nasal IMV group had less noninvasive failure $(P=.04)$ and a lower BPD rate $(P<.03)$.

Obviating invasive ventilation, with or without surfactant replacement, is an attractive option for reducing many of the complications experienced by premature neonates. Although the numbers of neonates enrolled in the studies have been small, nasal IMV appears to be a better alternative than CPAP in neonates with apnea and/or mild to moderate respiratory distress. Additional studies may be useful to evaluate the clinical effects of nasal IMV in neonates with moderate to severe respiratory distress as a rescue strategy, as a primary mode of noninvasive respiratory support, or following CPAP.

Management and Monitoring. A standardized approach to optimize nasal IMV delivery is unknown. Institutions considering nasal IMV for their patient population should consider reviewing the approaches used in clinical studies (see Tables 1-3) or collaborating with individuals from organizations with established management protocols. The ongoing clinical management during nasal IMV depends on careful patient monitoring and clinicians' ability to recognize differences in the pathophysiologic condition with changes in disease severity. Because of the inherently leaky nature of the nasal airway interface, lung mechanics and 
Neonatal Noninvasive Ventilation Techniques: Do We Really Need to Intubate?

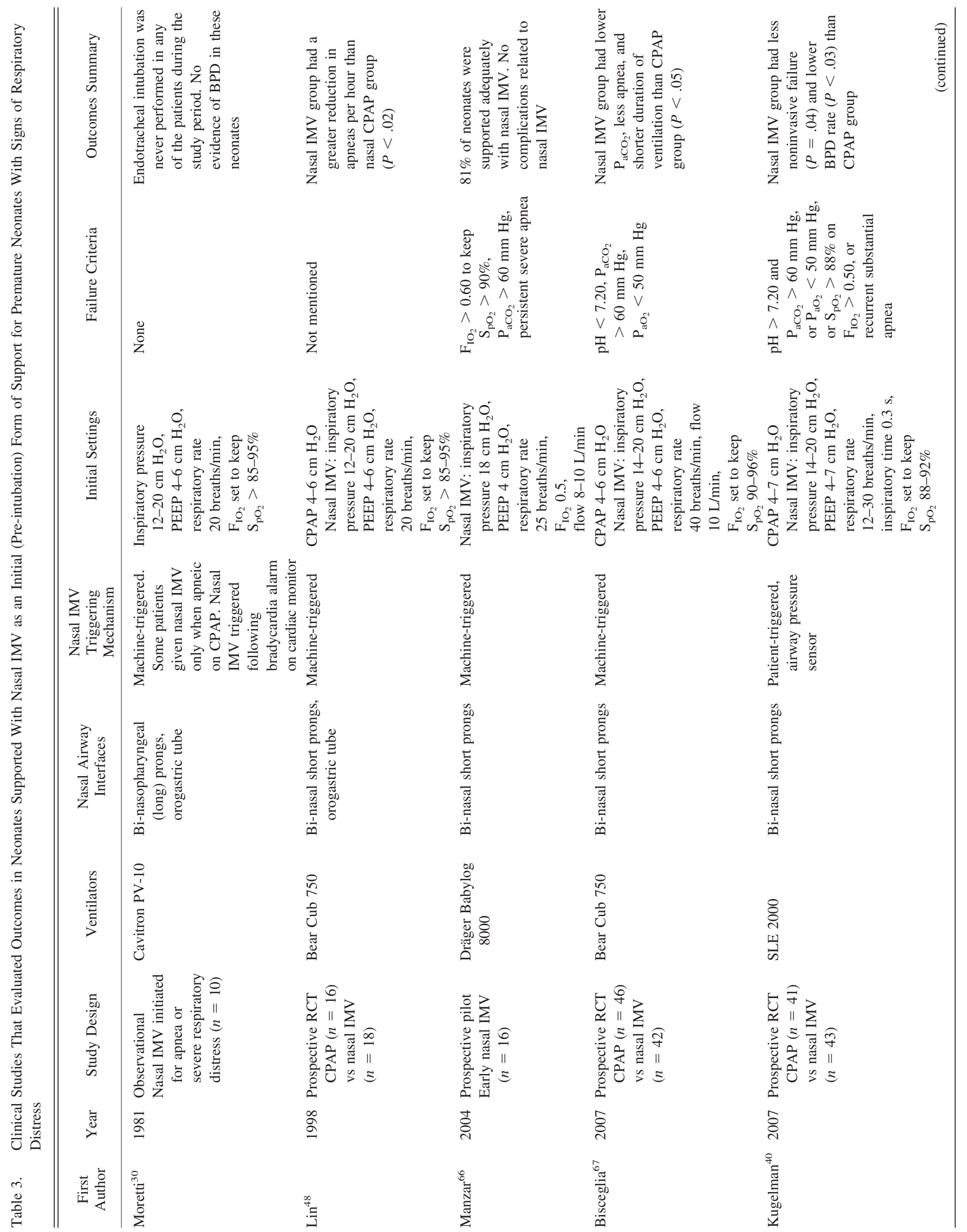




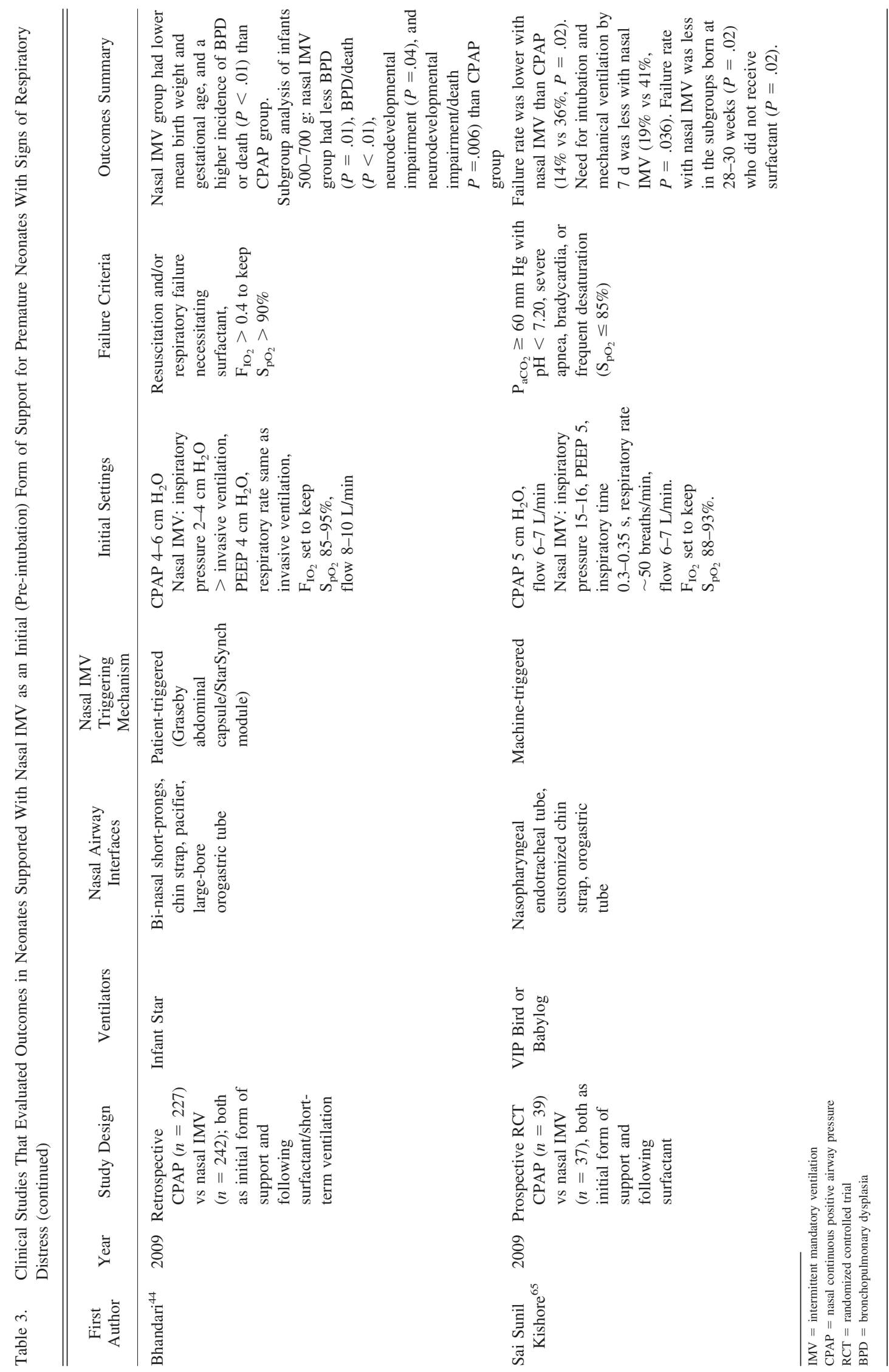


end-expiratory lung volume are not easily measured at the bedside during nasal IMV, so lung recruitment is assessed more on changes in respiratory distress, chest-wall expansion, WOB, and gas exchange. Some institutions use a respiratory scoring system such as the Silverman-Anderson score to evaluate respiratory distress and manage respiratory support and patient comfort. ${ }^{65}$ Chest radiograph may be useful to diagnose changes in patient condition, but is a poor surrogate for determining lung inflation. Transcutaneous $\mathrm{CO}_{2}$ monitoring and pulse oximetry may offer reliable correlates for determining gas exchange in patients supported by nasal IMV and are preferable to repeated analysis of blood samples, as long as correlation with blood gas values has been confirmed.

Few reports suggest a standardized weaning approach to nasal IMV, but some evidence suggests weaning, once neonates are at ventilator settings of PIP/PEEP 14/ $4 \mathrm{~cm} \mathrm{H}_{2} \mathrm{O}$, respiratory rate of $\leq 20$ breaths/min, and $\mathrm{F}_{\mathrm{IO}_{2}} \leq 0.3$, with acceptable blood gas values. ${ }^{63}$ The patient can then be transitioned to CPAP or high-flow nasal cannula. ${ }^{65}$

Not all neonates can be supported by nasal IMV alone, and intubation is indicated for severe ventilatory impairment $\left(\mathrm{pH}<7.25, \mathrm{P}_{\mathrm{aCO}_{2}}>60 \mathrm{~mm} \mathrm{Hg}\right)$, refractory hypoxemia $\left(\mathrm{P}_{\mathrm{aO}_{2}}<50 \mathrm{~mm} \mathrm{Hg}\right.$ on $\mathrm{F}_{\mathrm{IO}_{2}}$ of $\left.>0.6\right)$, and frequent apnea that does not respond to stimulation or intravenous caffeine therapy during IMV. ${ }^{64}$ No consensus exists on determining the maximal settings during nasal IMV. Owen et a ${ }^{55}$ showed that increasing the inspiratory pressure during nasal IMV may not always result in a linear increase in delivered pressure at the nasal airway interface. When inspiratory pressure was increased from 20 to $25 \mathrm{~cm} \mathrm{H}_{2} \mathrm{O}$, the pressure increase at the nasal prongs was only $1.3 \mathrm{~cm} \mathrm{H}_{2} \mathrm{O}$. In fact, one of the most likely reasons neonates fail nasal IMV is related to poor pressure transmission applied to the lungs, because of an inadequate seal between the tongue and soft palate, ${ }^{50}$ nasal airway interface, or as a consequence of the asynchrony that often occurs. As lung compliance decreases, a larger leak can develop. In some cases, upsizing the nasal prongs using a chin-strap, Cannulaide, or pacifier, may prevent excessive leak and improve pressure delivery in patients who are deteriorating on nasal IMV. ${ }^{44}$

\section{Nasal Neurally Adjusted Ventilatory Assist}

Nasal neurally adjusted ventilatory assist (NAVA) is a novel form of noninvasive respiratory support that uses the electrical activity of the diaphragm (EAdi) to determine the timing and magnitude of inspiratory pressure delivery during spontaneous breathing. The EAdi signal is obtained with an indwelling 5.5 French feeding tube equipped with 10 electrodes. The tube is placed in the esophagus so that the electrodes are at the level of the diaphragm. ${ }^{68,69}$ When

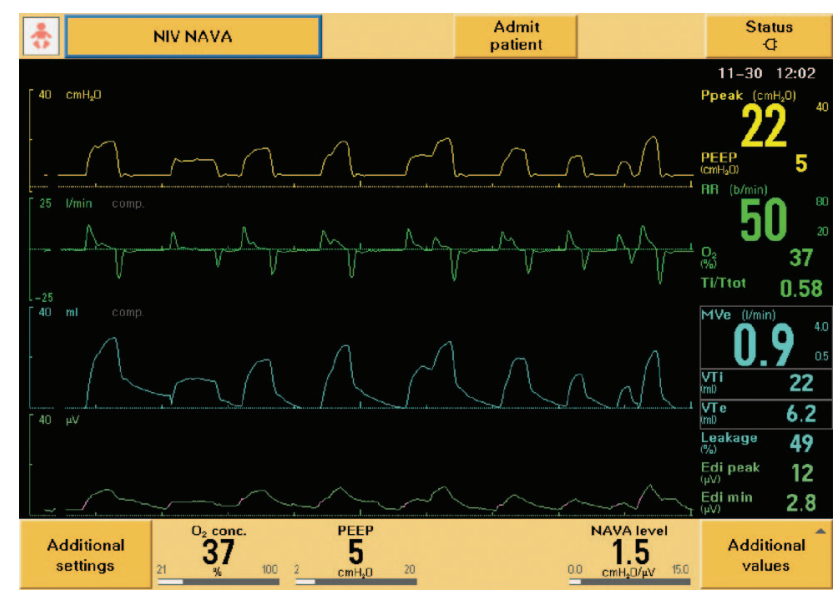

Fig. 5. Example ventilator screen during nasal neurally adjusted ventilatory assist in a premature neonate (23 weeks gestational age, $560 \mathrm{~g}$ ) with respiratory distress syndrome. The yellow, green, blue, and gray lines represent airway pressure, flow, volume, and electrical activity of the diaphragm (Edi) signal, respectively. The inspiratory pressure, trigger, and cycle is proportional to the Edi, and is captured with every spontaneous effort made by the patient. (Courtesy of Robert Tero RRT-NPS.)

positioned properly, the electrodes and consequent EAdi signal can accurately and reliably trigger and cycle a positive-pressure breath, independent of airway leak. Additionally, the magnitude of the inspiratory pressure assist is a product of the EAdi signal and the pre-set NAVA level. ${ }^{68,69}$ This feature has been available as an invasive mode with the Servo-i ventilator (Maquet, Solna, Sweden) for about 2 years, but was FDA approved for noninvasive application only recently. Nasal NAVA appears to work well, even in the smallest of patients. Figure 5 shows Servo-i ventilator graphics from a very-low birth-weight premature neonate during nasal NAVA.

NAVA has many proposed advantages over nasal IMV; however, only 2 reports have been published, from shortterm studies that evaluated patient-ventilator interaction during nasal NAVA. There have been no studies evaluating long-term outcomes in premature neonates on IMV, but many studies are underway.

Beck et al ${ }^{68}$ conducted a prospective controlled experiment in 10 lung-lavaged, spontaneously breathing juvenile rabbits. Following lung lavages the animals sequentially underwent (1) NAVA level 1 during invasive ventilation, with and without PEEP, (2) extubation with no support, and (3) NAVA with a single nasal prong, with progressively increasing NAVA levels and no PEEP. Blood gases, hemodynamics, and esophageal pressures were measured at each condition. Despite extremely leaky nasal airway interfaces (approximately 75\% leak), no differences were observed in the animals' abilities to initiate and cycle breaths between invasive and noninvasive NAVA. In addition, no differences were observed in gas exchange or 
gastric insufflation of gases during the study period. A nearly 4-fold increase in the NAVA level allowed the animals' spontaneous breathing efforts to be restored to the pre-extubation values. This required inspiratory pressure of approximately $15 \mathrm{~cm} \mathrm{H}_{2} \mathrm{O}$. In these hypoxemic animals, NAVA appears to be a reasonable NIV approach for unloading the respiratory system, promoting gas exchange, and improving synchrony, independent of leak.

A similar study by Beck et al ${ }^{69}$ was performed in 7 human premature neonates (25-29 weeks gestational age) with resolving lung disease and who were ready to be extubated. In the first phase of the study, a NAVA catheter was placed, and airway pressure and EAdi were measured during a 60 -min period on a conventional ventilator. The neonates were then placed on invasive NAVA at a level that provided airway pressure similar to that of conventional ventilation. Following a short period of NAVA, the neonates were extubated and supported with NAVA via a single nasal prong and at similar NAVA as when they were extubated. No PEEP was used because of excessive leak during NAVA. NAVA resulted in lower mean airway pressure $(P=.002)$ and higher oxygen requirement $(P=.003)$ than did the other testing conditions, due to poor pressure transmission from the leak. Interestingly, NAVA (without PEEP) resulted in a lower neural respiratory rate $(P=.004)$, less breath-cycling delay, and better correlation between EAdi and airway pressure $(P<.001)$ than did invasive ventilation. This short-term study identifies nasal NAVA as a reasonable way to support spontaneously breathing premature neonates following and potentially prior to intubation.

Similar to other forms of NIV, NAVA requires that the patient is breathing spontaneously. Premature neonates who are apneic may not be able to be supported by nasal NAVA, even with use of a back-up ventilator mode. These published studies were performed with a prototype Servo 300 ventilator (Maquet, Solna, Sweden), and NAVA is currently commercially available only on the Servo-i ventilator. Nasal NAVA is an invasive mode, requires frequent bedside attendance, and is relatively expensive. Future studies with larger numbers of neonates will help to assess outcomes to evaluate NAVA as a standard NIV approach for supporting neonates with lung disease.

\section{Sigh Continuous Positive Airway Pressure}

The Infant Flow nasal "sigh" positive airway pressure (SiPAP) device (Carefusion, Yorba Linda, California) is a second-generation noninvasive respiratory support device, similar to the Infant Flow Advance that is being used in Europe. This device is being implemented more frequently in NICUs to assist spontaneously breathing neonates with lung disease and apnea. Infant Flow SiPAP uses the same nasal prongs, mask, fixation, and fluidic-flip mechanism

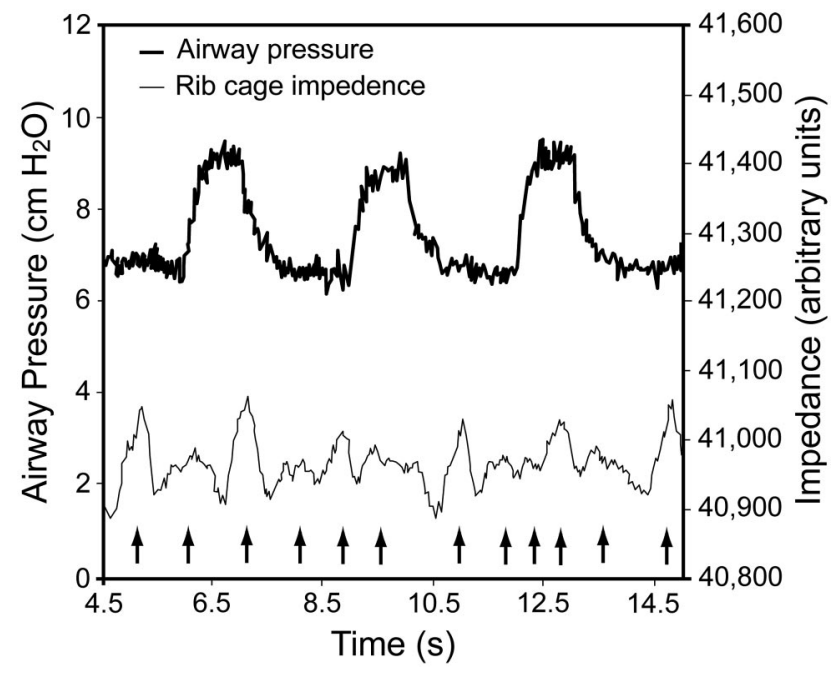

Fig. 6. Example airway pressure and rib-cage impedance in a premature infant supported with the biphasic mode of SiPAP ("sigh" positive airway pressure) from the Infant Flow nasal continuous positive airway pressure system. The arrows indicate patient-initiated breaths. (From Reference 70, with permission.)

used in Infant Flow nasal CPAP. SiPAP differs from other forms of NIV in that it allows the neonate to breathe continuously at 2 separate CPAP levels. The primary CPAP level is set at $4-6 \mathrm{~cm} \mathrm{H}_{2} \mathrm{O}$ by adjusting flow through a flow meter, and airway pressure is displayed by an internal manometer. The secondary CPAP level or "sigh" is set with a second flow meter, to obtain a pressure $2-4 \mathrm{~cm} \mathrm{H}_{2} \mathrm{O}$ higher than the baseline CPAP setting. The breath-hold is adjusted to between 0.5 second and 2 seconds, and the respiratory rate controls the frequency of intermittent "sigh" breaths (Fig. 6).

In combination with spontaneous breathing, these "sighs" are intended to recruit unstable air spaces, maintain endexpiratory lung volume, avoid apnea, and reduce the need for invasive ventilation. Alveolar ventilation depends on both the neonate's spontaneous $\dot{\mathrm{V}}_{\mathrm{E}}$ and the $\dot{\mathrm{V}}_{\mathrm{E}}$ created by SiPAP transitioning between the 2 CPAP levels. Outside the United States, SiPAP allows patient-triggered SiPAP breaths triggered with a Graseby capsule placed on the abdomen. In the United States, the Graseby capsule is used only to monitor respiratory rate. The rise in pressure from the primary CPAP level to the secondary CPAP level is gradual and differs from pressure support provided by conventional ventilators. Whether patient-triggering will be made available is unclear. Nonetheless, investigators are evaluating the effectiveness and physiologic benefits related to patient-triggering with this form of support.

In a small observational study, SiPAP provided better gas exchange than did standard CPAP in preterm infants. ${ }^{71}$ Ancora et $\mathrm{al}^{72}$ retrospectively evaluated whether SiPAP following surfactant administration and brief ventilation would prevent re-intubation and mechanical ventilation in 
preterm neonates. Neonates in the historical control group ( $n=22)$ were supported with $4-6 \mathrm{~cm} \mathrm{H}_{2} \mathrm{O} \mathrm{CPAP}$, and neonates in the SiPAP group $(n=38)$ were managed using primary $\mathrm{CPAP}$ at $4-6 \mathrm{~cm} \mathrm{H}_{2} \mathrm{O}$ and secondary CPAP at 5-8 $\mathrm{cm} \mathrm{H}_{2} \mathrm{O}$; time high was $0.5-0.6$ second, and the respiratory rate was $10-30$ cycles $/ \mathrm{min}$. The need for mechanical ventilation was greater in the historical control group than in the infants supported with SiPAP (27\% vs $0 \%, P=.001)$. The mothers of the infants in the SiPAP group had received antenatal steroids more frequently than had the historical control infants $(P=.003)$, which may help explain why re-intubation was not needed in the SiPAP infants. Nonetheless, SiPAP, combined with antenatal steroids and surfactant, appears to be an attractive initial clinical approach for preterm neonates.

In a prospective RCT, Lista et al ${ }^{73}$ compared outcomes in preterm neonates who received either CPAP $(n=20)$ or $\operatorname{SiPAP}(n=20)$ as the initial form of support in the acute phase of RDS. All the infants received sustained lung inflations in the delivery room and surfactant (as needed), with immediate extubation. Neonates in the CPAP group were supported with CPAP $6 \mathrm{~cm} \mathrm{H}_{2} \mathrm{O}$, and the settings in the SiPAP group were adjusted to provide similar mean airway pressure. Infants supported by SiPAP had shorter duration of mechanical ventilation $(P=.03)$, less $\mathrm{O}_{2}$ dependence $(P=.03)$, and were discharged sooner $(P=.02)$ with similar serum levels of pro-inflammatory cytokines (interleukin 6, interleukin 8, tumor necrosis factor alpha), as did the infants supported initially with CPAP. The study suggests that SiPAP is a more beneficial form of noninvasive support than is nasal CPAP at similar mean airway pressure, without increasing lung injury.

\section{Nasal High-Frequency Ventilation}

Invasive high-frequency ventilation is a form of lungprotective ventilation that is commonly used in neonates with lung disease, as an initial ventilation strategy or as a rescue intervention if a neonate fails conventional ventilation. In a premature baboon model, long-term HFOV resulted in better pulmonary mechanics, consistently more uniform lung inflation, and less pulmonary inflammation than did conventional ventilation with a low- $\mathrm{V}_{\mathrm{T}}$ strategy. ${ }^{74}$

In a recent meta-analysis ${ }^{75}$ of RCTs that compared outcomes in neonates supported by different forms of highfrequency ventilation or conventional ventilation, there were no differences in infant chronic lung disease, mortality, or neurological insult. However, when randomization occurred earlier (1-4 h), HFOV was associated with less death or BPD than was conventional ventilation $(P=.01)$.

Over the last 5 years, nasal high-frequency ventilation (HFV) has been used more commonly in clinical practice as a form of NIV. Unlike nasal IMV and SiPAP, nasal
HFV uses lower pressure and smaller volume at higher frequency, and may be more lung-protective than are other higher-pressure NIV modes. The most common ventilator used to apply nasal HFV is the Infrasonics Infant Star. Nasal HFV is applied via either nasopharyngeal ETT or bi-nasal prongs with fixation.

The physiologic mechanism through which nasal HFV supports spontaneously breathing neonates with RDS is unclear. Nasal HFV may improve gas exchange by providing higher mean airway pressure and pneumatic stenting of the laryngeal structures. The effects of high-frequency, small-amplitude pressure oscillations applied via nasal mask have been observed in healthy adults and in adults with obstructive sleep apnea. ${ }^{76}$ The most important finding from that study was that pressure oscillations were associated with a partial or complete reversal of the upperairway obstruction and $\mathrm{V}_{\mathrm{T}}$ increase. Those authors concluded that upper-airway receptors were responding to the low-pressure, high-frequency oscillations, with input to the genioglossus and other muscles of respiration. These responses may be important for improving ventilation and reducing the adverse effects of obstructive apnea during nasal HFV in neonates.

In a case study, Hoehn et al ${ }^{77}$ described the first successful application of nasal HFV in an extremely-lowbirth-weight $(760 \mathrm{~g})$ preterm (27 weeks gestational age) neonate with severe $\mathrm{CO}_{2}$ retention, acidemia, and respiratory distress. Re-intubation was avoided and $\mathrm{P}_{\mathrm{aCO}}$ and $\mathrm{pH}$ dramatically improved. The improvements in alveolar ventilation were probably related to the high-frequency pressure oscillations, which may enhance gas mixing in the upper airways through the process of facilitated augmented diffusion. Other proposed gas-exchange mechanisms have been described during nasal HFV that may not be present during conventional ventilation..$^{78}$

In a recent animal study, Reyburn et al ${ }^{79}$ tested the hypothesis that nasal HFV would result in less lung injury and better alveolar development than are observed with conventional invasive IMV. Two groups of premature lambs were administered surfactant, randomized to nasal HFV or invasive conventional ventilation, and supported for a 3-day period. The invasive conventional ventilation group was managed with a respiratory rate of 60 cycles/ min, inspiratory time of $0.3 \mathrm{~s}, \mathrm{~V}_{\mathrm{T}}$ of $7 \mathrm{~mL} / \mathrm{kg}$, and PEEP of $8 \mathrm{~cm} \mathrm{H}_{2} \mathrm{O}$. The nasal HFV group was managed with high-frequency percussive ventilation (VDR3, Percussionaire, Bird Technologies, Sandpoint, Idaho) attached to a nasopharyngeal tube placed into a single nare. The initial settings were amplitude $20-25 \mathrm{~cm} \mathrm{H}_{2} \mathrm{O}$, mean airway pressure $8-12 \mathrm{~cm} \mathrm{H}_{2} \mathrm{O}$, and frequency $10 \mathrm{~Hz}$. The 2 groups had similar gas-exchange goals, which guided subsequent ventilator adjustments and weaning over the study period. Nasal HFV resulted in smaller and more uniformly inflated terminal respiratory units and distal air spaces, lon- 

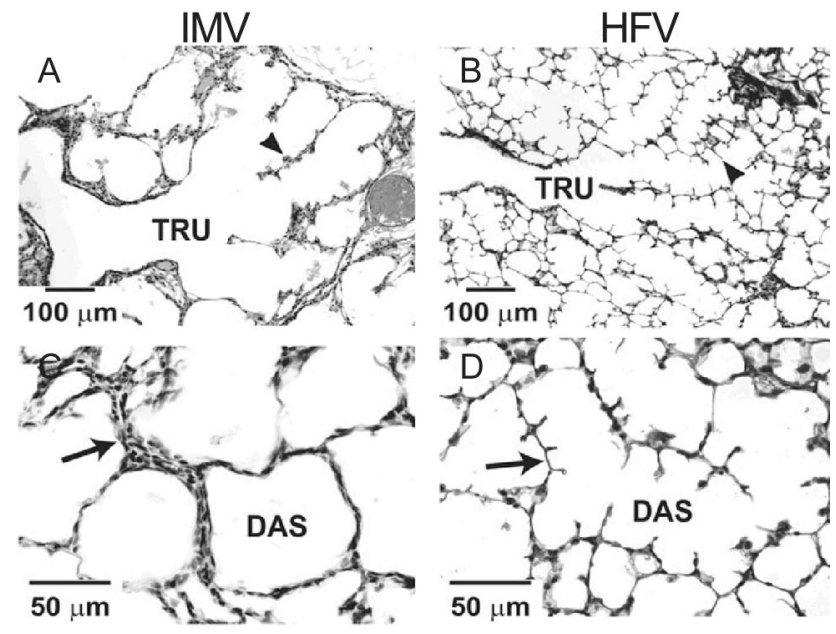

FA132
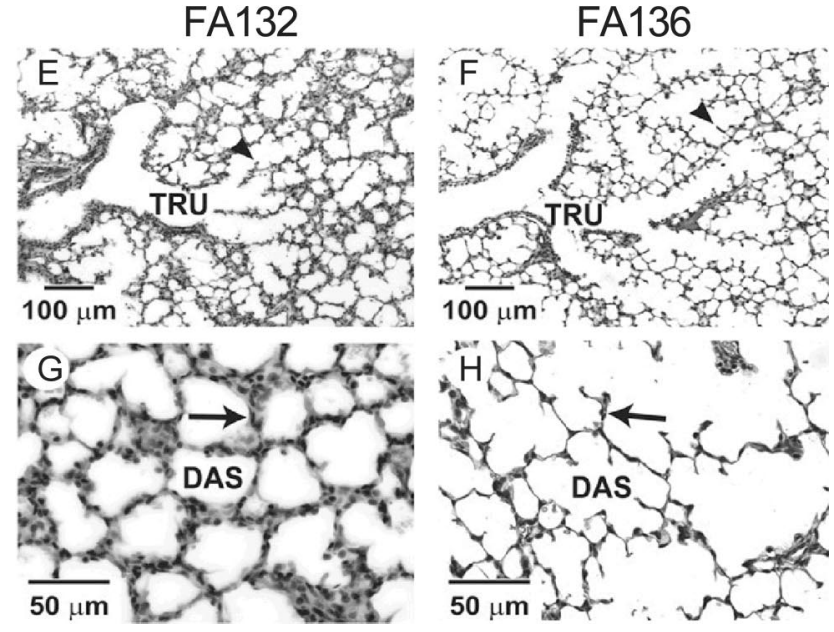

Fig. 7. Histology of lung tissue from preterm lambs ventilated for 3 days with invasive intermittent mandatory ventilation (IMV) (A and C) or noninvasively with nasal high-frequency ventilation (HFV) (B and D). Each row of panels has the same magnification (see scale bars). The gestation control fetal lambs were (1) delivered at the gestation age that the preterm lambs were delivered (FA132) or (2) delivered at the gestation age when the preterm lamb studies were completed (FA136). The terminal respiratory unit (TRUs) in the preterm lambs that received nasal HFV ( $B$ and $D)$ have smaller and more uniform distal air spaces (DASs), more and thinner alveolar secondary septa (arrowhead in A and B), and thinner distal air-space walls (arrow in C and $D$ ) than the TRUs in the preterm lambs that received IMV (A and C). The TRUs in the preterm lambs that received nasal HFV are structurally similar to the TRUs in the FA136 gestation control lambs ( $F$ and $H)$. On the other hand, the TRUs in the preterm lambs that received IMV (A and C) are structurally similar to the TRUs in the FA132 gestation control lambs (E and G). (From Reference 79, with permission.)

ger alveolar secondary septae, and thinner distal air-space walls than did invasive conventional ventilation $(P=.005$, Fig. 7). This implies that short-term nasal HFV may optimize lung recruitment and promote normal alveolarization in preterm lungs better than does a "gentle" invasive ventilation strategy. Additionally, at days 2 and 3, lower $\mathrm{F}_{\mathrm{IO}_{2}}$ was required during nasal $\mathrm{HFV}$ than during invasive ventilation $(P=.005)$.
Of particular interest was the fact that the investigators measured intratracheal pressure in the animals receiving nasal HFV, and the delivered pressure averaged only $0.37 \pm 0.23 \mathrm{~cm} \mathrm{H}_{2} \mathrm{O}$. These data imply a large leak at the nasal airway interface with the nasopharyngeal ETT. Whether bi-nasal prongs are more effective in providing ventilation is not resolved by these data. Conversely, it is unclear whether using bi-nasal prongs during HFV results in greater volutrauma, gas trapping, and lung injury and less favorable alveolarization than does HFV via nasopharyngeal ETT.

Unfortunately, nasal HFV is such a new form of NIV that very few data are available to suggest a long-term management strategy in neonatal patients. Short-term observational studies have suggested initial mean airway pressure set to equal the previous CPAP, frequency set at $10 \mathrm{~Hz}$, amplitude adjusted to obtain visible chest-wall vibration and increased every $30 \mathrm{~min}$ by 4-6 units, if necessary, to maintain clinically appropriate chest-wall vibration, transcutaneous $\mathrm{CO}_{2}$, or blood gas values. ${ }^{80,81}$

Clinical responses to $\mathrm{HFV}$ in preterm neonates in 2 small studies have been reported. Van der Hoeven et al ${ }^{79}$ placed 21 preterm and term infants with moderate respiratory insufficiency on nasal $\mathrm{HFV}$ following CPAP. A nasopharyngeal ETT was placed $3-4 \mathrm{~cm}$ into a single nare, and HFV was provided with the Infant Star ventilator in the high-frequency flow-interrupter mode, with mean airway pressure settings similar to or higher than the previous CPAP setting, frequency of $10 \mathrm{~Hz}$; amplitude was increased until chest-wall oscillations were observed. Initiation of $\mathrm{HFV}$ following CPAP resulted in a small reduction in $\mathrm{P}_{\mathrm{aCO}_{2}}(P=.001)$ but no significant change in $\mathrm{pH}$. Five $(23 \%)$ of the patients failed nasal $\mathrm{HFV}$ and required invasive ventilation related to severe RDS, sepsis, and apnea.

Colaizy et al $^{81}$ performed a similar observational study to compare the clinical effects of nasal HFV to CPAP in neonates with mild to moderate lung disease. All 14 subjects were very-low-birth-weight infants $(<1,500 \mathrm{~g})$ who were transitioned from CPAP to HFV via nasopharyngeal ETT, with the Infant Star ventilator in the high-frequency, flow-interrupter mode. The investigators used an approach similar to that of van der Hoeven et al, ${ }^{80}$ for 2 hours. After 2 hours of nasal HFV, capillary blood gases were measured and the subjects were returned to their pre-study CPAP settings. Nasal HFV decreased mean transcutaneous $\mathrm{P}_{\mathrm{CO}_{2}}$ from $50 \mathrm{~mm} \mathrm{Hg}$ to $45 \mathrm{~mm} \mathrm{Hg}(P=.01)$ and increased $\mathrm{pH}$ from 7.40 to $7.37(P=.04)$. In all the infants, chest radiograph obtained 1 hour after nasal $\mathrm{HFV}$ provided no evidence of hyperinflation.

Dumas de la Roque et al ${ }^{82}$ performed a prospective RCT of nasal CPAP versus nasal HFV in 40 term neonates with respiratory distress shortly after cesarean section. This was the first short-term prospective study to describe nasal $\mathrm{HFV}$ as an initial form of noninvasive respiratory support 
in neonates. Neonates randomized to CPAP were supported with $5 \mathrm{~cm}$ of CPAP, and neonates in the nasal HFV group were supported with the VDR3 high-frequency percussion device, with an initial mean airway pressure of $5 \mathrm{~cm} \mathrm{H}_{2} \mathrm{O}$ and a frequency of $5 \mathrm{~Hz}$. The groups had similar oxygenation goals, and the settings were not changed throughout the study period. Lung disease resolved in all the neonates within 10 hours, but the nasal HFV group had shorter duration of respiratory distress, lower oxygen therapy level, and shorter oxygen therapy duration $(P<.001)$ than did the CPAP group.

Some clinicians are concerned that pressure oscillations delivered out of phase with the neonate's spontaneous breathing efforts may impose high WOB. Although the complex interplay between spontaneous breathing and HFV has not been described in the literature, van Heerde et al ${ }^{83}$ found a low imposed WOB during invasive HFOV, with the 3100A HFOV ventilator (Carefusion, Yorba Linda, California) in a simulated spontaneously breathing neonate. How these data would compare to bi-nasal prongs or a nasopharyngeal ETT is unclear, but the effects are not likely to be similar due to the inherently leaky nature and lower imposed resistances of these nasal airway interfaces. Carlo $^{84}$ has suggested that a potential advantage of nasal HFV over IMV is that synchronization is not necessary, due to the relatively high frequencies. However, studies to test this hypothesis in neonates are needed.

The widespread use of nasal HFV in neonates with broadly different lung diseases cannot be suggested at this time, but HFV appears to be an NIV mode that will be evaluated in future clinical trials. The majority of the aforementioned studies were in animals and humans and used high-frequency flow-interrupter or high-frequency percussive ventilation strategies, and the most frequently used of those devices, the Infant Star ventilator, is now obsolete. As such, there is interest in using nasal HFV with the widely used 3100A HFOV ventilator. Whether this ventilator has been used off-label to provide HFV in neonates is unclear. The ventilator circuit is more rigid than are standard ventilator circuits, which creates difficulties in interfacing with nasal prongs without causing unnecessary torque on the neonate's airway. Further, the 3100A has a pressure-relief ("dump") valve that is activated by electronic and pneumatic controls that open the patient circuit to ambient air when the measured mean airway pressure reaches $<20 \%$ of the maximum set mean airway pressure. This factor may be a limitation in spontaneously breathing neonates using mean airway pressure (approximately $5 \mathrm{~cm} \mathrm{H}_{2} \mathrm{O}$ ) similar to those previously described in shortterm human neonatal HFV studies.

De Luca et al ${ }^{85}$ evaluated the effect of ventilation parameters during nasal HFOV in a bench study with the 3100A HFOV ventilator. Nasal HFOV was applied to a neonatal test lung with a prototype adapter/circuit and bi- nasal short prongs (Argyle CPAP nasal cannula, Sherwood Medical, St Louis, Missouri) of 2 different diameters (large and small), without a leak. Oscillatory volume, $\dot{V}_{\mathrm{E}}$, and mean airway pressure were measured at several mean airway pressures and $\mathrm{Hz}$ settings. The power level was adjusted to obtain an amplitude of $45 \mathrm{~cm} \mathrm{H}_{2} \mathrm{O}$ for the entire study. Data from HFV were compared to a "control circuit" invasive HFOV simulation, wherein the HFOV circuit was attached directly to the neonatal lung model (without prongs or an ETT). The pressure drops between the nasal airway and test lung were calculated as $38.5 \pm 10.9 \%$, $35.3 \pm 10.1 \%$, and $22.1 \pm 10.4 \%$, for the small prongs, large prongs, and control circuit, respectively. $\mathrm{V}_{\mathrm{T}}$ was $0.4 \pm 0.1,0.9 \pm 0.3$, and $1.5 \pm 0.5$ for small prong, large prong, and the control circuit, respectively. The pressure delivered to the neonatal lung via the bi-nasal prongs in that study are much larger than those observed by Reyburn et al, ${ }^{79}$ when tracheal pressure was measured in preterm lambs. Conversely, data from the bench study were obtained in the absence of a leak. These differences warrant further investigation, to compare the effects of gas trapping and lung injury between nasopharyngeal ETT and short bi-nasal prong interfaces during HFV.

Based on these small, short-term studies, nasal HFV appears to be technically possible in preterm neonates. However, more bench and animal studies are needed, using different nasal airway interfaces with the available high-frequency ventilators, before long-term studies are performed in human neonates with severe lung disease.

Bubble CPAP is a form of noninvasive respiratory support that is being called "inexpensive nasal HFV," because the bubbling in the water-seal creates small-amplitude, high-frequency oscillations that are transmitted to the nasal airway interface of spontaneously breathing neonates. Animal studies ${ }^{86,87}$ and studies in human neonates ${ }^{88}$ have shown that bubble CPAP may result in better alveolar ventilation and lung recruitment than conventional (ventilator-derived) CPAP. However, those studies were conducted in subjects who were endotracheally intubated, and no studies have evaluated these physiologic effects in subjects with a leaky nasal airway interface. In a recent bench test, bubble CPAP, applied with leaky bi-nasal short prongs, resulted in measureable volume oscillations (approximately 0.5-0.6 mL) delivered to a neonatal nasal airway/test lung. ${ }^{89}$ Clinicians often increase the bias flow to increase the amplitude and frequency of airway pressure oscillations during bubble CPAP, but this practice has not been shown to enhance gas exchange or lung recruitment. ${ }^{90}$

In 2010, 2 reports appeared ${ }^{91,92}$ of a novel high-amplitude bubble-CPAP system that can provide a greater level of NIV support than conventional bubble CPAP alone. Controlling the angle through which gas exits, the bubbleCPAP water-seal column was reported to enhance greatly the airway-pressure oscillations at the nasal airway inter- 
face, thus providing flexibility to meet the differing requirements of patients with differing levels of respiratory distress. In a neonatal lung model with leaky nasal prongs, the high-amplitude bubble-CPAP device adjusted with the outlet tubing at $135^{\circ}$, in relation to the water surface level, delivered $\mathrm{V}_{\mathrm{T}}$ similar to that previously measured during HFOV in infants. ${ }^{93}$ In addition, high-amplitude bubble CPAP provided noninvasive support, via bi-nasal prongs, to spontaneously breathing, lung-lavaged juvenile rabbits with lower WOB $(P<.001)$ and higher $\mathrm{P}_{\mathrm{aO}_{2}}(P=.007)$ than were observed in the same animals supported with bubble CPAP at identical mean airway pressures. ${ }^{91}$ Two rabbits supported by high-amplitude bubble CPAP became apneic, with normal $\mathrm{P}_{\mathrm{aCO}_{2}}$ and vital signs. High-amplitude bubble CPAP may represent a relatively simple new strategy for supporting a greater fraction of neonates who would otherwise fail CPAP and require invasive ventilation. Neonatal clinical trials are needed to test this hypothesis.

\section{Summary}

The prevailing message from this comprehensive review suggests that there is a large population of neonatal patients who cannot be supported by CPAP, and the clinical consensus is that invasive ventilation should be avoided at "all cost" to the patient. The advent of neonatal airway interfaces has ushered in a whole new generation of NIV strategies for neonatal patients, specifically those affected by RDS. In the not so distant future, clinicians may rely more on IMV, SiPAP, NAVA, and HFV as the established initial NIV approach for supporting infants at risk for developing most forms of neonatal respiratory distress. It is unlikely that these strategies will completely obviate invasive ventilation, but they may reduce the need for repeated intubation and prolonged ventilation, and so may reduce the numerous complications that affect this sensitive patient population. While still early in its inception, clinicians will need further clinical research to determine the "best" form of NIV that satisfies their patient population and embraces development of disease-specific management strategies.

\section{REFERENCES}

1. Singh GK, Yu SM. Infant mortality in the United States: trends, differentials, and projections, 1950 through 2010. Am J Public Health 1995;85(7):957-964.

2. Jobe AH, Kramer BW, Moss TJ, Newnham JP, Ikegami M. Decreased indicators of lung injury with continuous positive expiratory pressure in preterm lambs. Pediatr Res 2002;52(3):387-392.

3. Björklund LJ, Ingimarsson J, Cursted T, John J, Robertson B, Werner O, et al. Manual ventilation with a few large breaths at birth compromises the therapeutic effect of subsequent surfactant replacement in immature lambs. Pediatr Res 1997;42(3):348-355.

4. Thomson MA, Yoder BA, Winter VT, Giavedoni L, Chang LY, Coalson JJ. Delayed extubation to nasal continuous positive airway pressure in the immature baboon model of bronchopulmonary dysplasia: lung clinical and pathological findings. Pediatrics 2006;118(5):2038-50.
5. Thibeault DW, Mabry SM, Ekekezie II, Zhang X, Truog WE. Collagen scaffolding during development and its deformation with chronic lung disease. Pediatrics 2003;111(4 Pt 1):766-776.

6. Jobe AJ. The new BPD: an arrest of lung development. Pediatr Res 1999;46(6):641-643.

7. Dreyfuss D, Saumon G. Barotrauma is volutrauma but which volume is the one responsible? Intensive Care Med 1992;18(3):139-141.

8. Muscedere JG, Mullen JB, Gan K, Slutsky AS. Tidal ventilation at low airway pressures can augment lung injury. Am J Respir Crit Care Med 1994;149(5):1327-1334.

9. Lista G, Castoldi F, Fontana P, Reali R, Reggiani A, Bianchi S, Compagnoni G. Lung inflammation in preterm infants with respiratory distress syndrome: effects of ventilation with different tidal volumes. Pediatr Pulmonol 2006;41(4):357-363.

10. Avery ME, Tooley WH, Keller JB, Hurd SS, Bryan MH, Cotton RB, et al. Is chronic lung disease in low birth weight infants preventable? A survey of eight centers. Pediatrics 1987;79(1):26-30.

11. Van Marter LJ, Allred EN, Pagano M, Sanocka U, Parad R, Moore M, et al. Do clinical markers of barotrauma and oxygen toxicity explain interhospital variation in rates of chronic lung disease? Pediatrics 2000; 105(6):1194-201.

12. Hutchison AA, Bignall S. Non-invasive positive pressure ventilation in the preterm neonate: reducing endotrauma and the incidence of bronchopulmonary dysplasia. Arch Dis Child Fetal Neonatal Ed 2008;93(1): F64-F68.

13. Aly H. Ventilation without tracheal intubation. Pediatrics 2009;124(2): 786-789.

14. te Pas AB, Wong C, Kamlin CO, Dawson JA, Morley CJ, Davis PG. Breathing patterns in preterm and term infants immediately after birth. Pediatr Res 2009;65(3):352-356.

15. Apisarnthanarak A, Holzmann-Pazgal G, Hamvas A, Olsen MA, Fraser VJ. Ventilator-associated pneumonia in extremely preterm neonates in a neonatal intensive care unit: characteristics, risk factors, and outcomes. Pediatrics 2003;112(6 Pt 1):1283-1289.

16. DiBlasi RM. Nasal continuous positive airway pressure (CPAP) for the respiratory care of the newborn infant. Respir Care 2009;54(9):12091235.

17. SUPPORT Study Group of the Eunice Kennedy Shriver NICHD Neonatal Research Network; Finer NN, Carlo WA, Walsh MC, Rich W, Gantz MG, Laptook AR, et al. Early CPAP versus surfactant in extremely preterm infants. N Engl J Med 2010;362(21):1970-1979. Erratum in: N Engl J Med 2010;362(23):2235.

18. Morley CJ, Davis PG, Doyle LW, Brion LP, Hascoet JM, Carlin JB; COIN Trial Investigators. Nasal CPAP or intubation at birth for very preterm infants. N Engl J Med 2008 Feb 14;358(7):700-708.

19. Stefanescu BM, Murphy WP, Hansell BJ, Fuloria M, Morgan TM, Aschner JL. A randomized, controlled trial comparing two different continuous positive airway pressure systems for the successful extubation of extremely low birth weight infants. Pediatrics 2003;112(5):10311038 .

20. Verder H, Albertsen P, Ebbesen F, Greisen G, Robertson B, Bertelsen A, et al. Nasal continuous positive airway pressure and early surfactant therapy for respiratory distress syndrome in newborns of less than 30 weeks' gestation. Pediatrics 1999;103(2):24.

21. Donald I, Lord J. Augmented respiration; studies in atelectasis neonatorum. Lancet 1953;1(6749):9-17.

22. Gregory GA, Kitterman JA, Phibbs RH, Tooley WH, Hamilton WK. Treatment of the idiopathic respiratory-distress syndrome with continuous positive airway pressure. N Engl J Med 1971;284(25):1333-1340.

23. Stern L, Ramos AD, Outerbridge EW, Beaudry PH. Negative pressure artificial respiration: use in treatment of respiratory failure of the newborn. Can Med Assoc J 1970;102(6):595-601.

24. Llewellyn MA, Tilak KS, Swyer PR. A controlled trial of assisted ventilation using an oro-nasal mask. Arch Dis Child 1970;45(242):453-459. 
25. Helmrath TA, Hodson WA, Oliver TK. Positive pressure ventilation in the newborn infant: the use of a face mask. J Pediatr 1970;76(2):202207.

26. Pape KE, Armstrong DL, Fitzhardinge PM. Central nervous system patholgoy associated with mask ventilation in the very low birthweight infant: a new etiology for intracerebellar hemorrhages. Pediatrics 1976; 58(4):473-483.

27. Allen LP, Blake AM, Durbin GM, Ingram D, Reynolds EO, Wimberley PD. Continuous positive airway pressure and mechanical ventilation by facemask in newborn infants. BMJ 1975;4(5989):137-139.

28. Kattwinkel J, Fleming D, Cha CC, Fanaroff AA, Klaus MH. A device for administration of continuous positive airway pressure by the nasal route. Pediatrics 1973;52(1):131-134.

29. Caliumi-Pellegrini G, Agostino R, Orzalesi M, Nodari S, Marzetti G, Savignoni PG, et al. Twin nasal cannulae Arch Dis Child 1974;49(3): 228-230.

30. Moretti C, Marzetti G, Agostino A, Panero A, Picece-Bucci S, Mendicini $\mathrm{M}$ et al. Prolonged intermittent positive pressure ventilation by nasal prongs in intractable apnea of prematurity. Acta Paediatr Scand 1981; 70(2):211-216.

31. Garland JS, Nelson DB, Rice T, Neu J. Increased risk of gastrointestinal perforations in neonates mechanically ventilated with either face mask or nasal prongs. Pediatrics 1985;76(3):406-410.

32. Friedlich P, Lecart C, Posen R, Ramicone E, Chan L, Ramanathan R. A randomized trial of nasopharyngeal-synchronized intermittent mandatory ventilation versus nasopharyngeal continuous positive airway pressure in very low birth weight infants after extubation. J Perinatol 1999; 19(6 Pt 1):413-418.

33. De Paoli AG, Morley CJ, Davis PG, Lau R, Hingeley E. In vitro comparison of nasal continuous positive airway pressure devices for neonates. Arch Dis Child Fetal Neonatal Ed 2002;87(1):42-45.

34. Owen LS, Morley CJ, Davis PG. Neonatal nasal intermittent positive pressure ventilation: a survey of practice in England. Arch Dis Child Fetal Neonatal Ed. 2008;93(2):F148-F150.

35. Stucki P, Perez MH, Scalfaro P, de Halleux Q, Vermeulen F, Cotting J. Feasibility of non-invasive pressure support ventilation in infants with respiratory failure after extubation: a pilot study. Intensive Care Med 2009;35(9):1623-1627.

36. Ali N, Claure N, Alegria X, D'Ugard C, Organero R, Bancalari E. Effects of non-invasive pressure support ventilation (NI-PSV) on ventilation and respiratory effort in very low birth weight infants. Pediatr Pulmonol 2007;42(8):704-710.

37. Owen LS, Morley CJ, Davis PG. Pressure variation during ventilator generated nasal intermittent positive pressure ventilation in preterm infants. Arch Dis Child Fetal Neonatal Ed. 2010;95(5):F359-F364.

38. Moretti C, Gizzi C, Papoff P, Lampariello S, Capoferri M, Calcagnini G, Bucci G. Comparing the effects of nasal synchronized intermittent positive pressure ventilation (nSIPPV) and nasal continuous positive airway pressure (nCPAP) after extubation in very low birth weight infants. Early Hum Dev 1999;56(2-3):167-177.

39. Nonaka S, Katada A, Nakajima K, Ohsaki T, Unno T. The effects of nasal flow stimulation on central respiratory pattern. Am J Rhinol 1995; 9:203-208

40. Kugelman A, Feferkorn I, Riskin A, Chistyakov I, Kaufman B, Bader D. Nasal intermittent mandatory ventilation versus nasal continuous positive airway pressure for respiratory distress syndrome: a randomized, controlled, prospective study. J Pediatr. 2007;150(5):521-526.

41. Greenough A, Dimitriou G, Prendergast M, Milner AD. Synchronized mechanical ventilation for respiratory support in newborn infants. Cochrane Database Syst Rev 2008;(1):CD000456.

42. Chang HY, Claure N, D'ugard C, Torres J, Nwajei P, Bancalari E. Effects of synchronization during nasal ventilation in clinically stable preterm infants. Pediatr Res 2011;69(1):84-89.
43. Kiciman NM, Andréasson B, Bernstein G, Mannino FL, Rich W, Henderson C, Heldt GP. Thoracoabdominal motion in newborns during ventilation delivered by endotracheal tube or nasal prongs. Pediatr Pulmonol 1998;25(3):175-181.

44. Bhandari V, Finer NN, Ehrenkranz RA, Saha S, Das A, Walsh MC, et al; Eunice Kennedy Shriver National Institute of Child Health and Human Development Neonatal Research Network. Synchronized nasal intermittent positive-pressure ventilation and neonatal outcomes. Pediatrics 2009;124(2):517-526.

45. Aghai ZH, Saslow JG, Nakhla T, Milcarek B, Hart J, Lawrysh-Plunkett $\mathrm{R}$, et al. Synchronized nasal intermittent positive pressure ventilation (SNIV) decreases work of breathing (WOB) in premature infants with respiratory distress syndrome (RDS) compared to nasal continuous positive airway pressure (NCPAP). Pediatr Pulmonol 2006;41(9):875-881.

46. Kugelman A, Bar A, Riskin A, Chistyakov I, Mor F, Bader D. Nasal respiratory support in premature infants: short-term physiological effects and comfort assessment. Acta Paediatr 2008;97(5):557-561.

47. Kulkarni A, Ehrenkranz RA, Bhandari V. Effect of introduction of synchronized nasal intermittent positive-pressure ventilation in a neonatal intensive care unit on bronchopulmonary dysplasia and growth in preterm infants. Am J Perinatol 2006;23(4):233-240.

48. Lin CH, Wang ST, Lin YJ, Yeh TF. Efficacy of nasal intermittent positive pressure ventilation in treating apnea of prematurity. Pediatr Pulmonol 1998;26(5):349-353.

49. Barrington KJ, Bull D, Finer NN. Randomized trial of nasal synchronized intermittent mandatory ventilation compared with continuous positive airway pressure after extubation of very low birth weight infants. Pediatrics 2001;107(4):638-641.

50. Ryan CA, Finer NN, Peters KL. Nasal intermittent positive-pressure ventilation offers no advantages over nasal continuous positive airway pressure in apnea of prematurity. Am J Dis Child 1989;143(10):11961198.

51. Head H. On the Regulation of Respiration: PART I. Experimental. J Physiol. 1889;10(1-2):1-152.

52. Greenough A, Morley CJ, Davis JA. Respiratory reflexes in ventilated premature babies. Early Hum Dev 1983;8(1):65-75.

53. Greenough A, Morley CJ, Davis JA. Provoked augmented inspirations in ventilated premature babies. Early Hum Dev 1984;9(2):111-117.

54. Lampland AL, Meyers PA, Worwa CT, Swanson EC, Mammel MC. Gas exchange and lung inflammation using nasal intermittent positivepressure ventilation versus synchronized intermittent mandatory ventilation in piglets with saline lavage-induced lung injury: an observational study. Crit Care Med 2008;36(1):183-187.

55. Owen LS, Morley CJ, Davis PG. [2010] [4407.298] Ventilator generated nasal intermittent positive pressure ventilation (NIPPV): can delivered pressure be improved? A randomized crossover study (abstract). Pediatric Academic Societies' Abstract Archive 2010. http://www. abstracts2view.com/pasall/search.php? search $=$ do \& intMaxHits $=10 \&$ where $\% 5 \mathrm{~B} \% 5 \mathrm{D}=$ \&andornot $\% 5 \mathrm{~B} \% 5 \mathrm{D}=\&$ query $=$ Owen. Accessed on July 15, 2011.

56. Ramanathan R, Sekar K, Rasmussen M, Bhatia J, Soll R. Nasal intermittent positive pressure ventilation (nippv) versus synchronized intermittent mandatory ventilation (simv) after surfactant treatment for respiratory distress syndrome (rds) in preterm infants $<30$ weeks' gestation: multicenter, randomized, clinical trial. http://www.pas-meeting.org/ 2009baltimore/abstracts/lb\%20pub\%20all_full\%20text\%2009.pdf. Accessed July 9, 2011.

57. Ramanathan R, Crotwell D, DiBlasi R. A novel means for delivering nasal intermittent positive pressure ventilation (nippv) in infants: the nasal cannula. http://www.seattlechildrens.org/doc/56th-AARC-intlresp-congress-detail.doc. Accessed July 7, 2011.

58. Lagarde S, Semjen F, Nouette-Gaulain K, Masson F, Bordes M, Meymat Y, Cros AM. Facemask pressure-controlled ventilation in children: what is the pressure limit? Anesth Analg 2010;110(6):1676-1679. 
59. Davis PG, Henderson-Smart DJ. Nasal continuous positive airways pressure immediately after extubation for preventing morbidity in preterm infants. Cochrane Database Syst Rev 2003;(2):CD000143.

60. Khalaf MN, Brodsky N, Hurley J, Bhandari V. A prospective randomized, controlled trial comparing synchronized nasal intermittent positive pressure ventilation versus nasal continuous positive airway pressure as modes of extubation. Pediatrics 2001;108(1):13-17.

61. Davis PG, Lemyre B, De Paoli AG. Nasal intermittent positive pressure ventilation (NIV) versus nasal continuous positive airway pressure (NCPAP) for preterm neonates after extubation. Cochrane Database Syst Rev 2001;(3):CD003212. DOI: 10.1002/14651858. CD003212.

62. Soll RF, Morley CJ. Prophylactic versus selective use of surfactant in preventing morbidity and mortality in preterm infants. Cochrane Database Syst Rev 2001;(2):CD000510.

63. Santin R, Brodsky N, Bhandari V. A prospective observational pilot study of synchronized nasal intermittent positive pressure ventilation (SNIV) as a primary mode of ventilation in infants $>$ or $=28$ weeks with respiratory distress syndrome (RDS). J Perinatol 2004;24(8):487493.

64. Bhandari V, Gavino RG, Nedrelow JH, Pallela P, Salvador A, Ehrenkranz RA, Brodsky NL. A randomized controlled trial of synchronized nasal intermittent positive pressure ventilation in RDS. J Perinatol 2007; 27(11):697-703.

65. Sai Sunil Kishore M, Dutta S, Kumar P. Early nasal intermittent positive pressure ventilation versus continuous positive airway pressure for respiratory distress syndrome. Acta Paediatr 2009;98(9):1412-1415.

66. Manzar S, Nair AK, Pai MG, Paul J, Manikoth P, Georage M, Al-Khusaiby SM. Use of nasal intermittent positive pressure ventilation to avoid intubation in neonates. Saudi Med J. 2004;25(10): 1464-1467.

67. Bisceglia M, Belcastro A, Poerio V, Raimondi F, Mesuraca L, Crugliano C, Corapi UP. A comparison of nasal intermittent versus continuous positive pressure delivery for the treatment of moderate respiratory syndrome in preterm infants. Minerva Pediatr 2007;59(2):91-95.

68. Beck J, Campoccia F, Allo JC, Brander L, Brunet F, Slutsky AS, Sinderby C. Improved synchrony and respiratory unloading by neurally adjusted ventilatory assist (NAVA) in lung-injured rabbits. Pediatr Res 2007;61(3):289-294.

69. Beck J, Reilly M, Grasselli G, Mirabella L, Slutsky AS, Dunn MS, Sinderby C. Patient-ventilator interaction during neurally adjusted ventilatory assist in low birth weight infants. Pediatr Res 2009;65(6):663668.

70. DiBlasi RM, Richardson CP. Continuous positive airway pressure. In: Walsh BK, Czervinske M, DiBlasi RM, editors. Perinatal and pediatric respiratory care, 3rd edition. St Louis: Elsevier 2009:305-324.

71. Migliori C, Motta M, Angeli A, Chirico G. Nasal bilevel vs. continuous positive airway pressure in preterm infants. Pediatr Pulmonol 2005; 40(5):426-430.

72. Ancora G, Maranella E, Grandi S, Pierantoni L, Guglielmi M, Faldella G. Role of bilevel positive airway pressure in the management of preterm newborns who have received surfactant. Acta Paediatr 2010;99(12): 1807-1811.

73. Lista G, Castoldi F, Fontana P, Daniele I, Cavigioli F, Rossi S, et al. Nasal continuous positive airway pressure (CPAP) versus bi-level nasal CPAP in preterm babies with respiratory distress syndrome: a randomized control trial. Arch Dis Child Fetal Neonatal Ed 2010;95(2):F85F89.

74. Yoder BA, Siler-Khodr T, Winter VT, Coalson JJ. High-frequency oscillatory ventilation: effects on lung function, mechanics, and airway cytokines in the immature baboon model for neonatal chronic lung disease. Am J Respir Crit Care Med 2000;162(5):1867-1876.

75. Cools F, Askie LM, Offringa M, Asselin JM, Calvert SA, Courtney SE, et al.; PreVILIG collaboration. Elective high-frequency oscillatory ver- sus conventional ventilation in preterm infants: a systematic review and meta-analysis of individual patients' data. Lancet 2010;375(9731):20822091.

76. Henke KG, Sullivan CE. Effects of high-frequency oscillating pressures on upper airway muscles in humans. J Appl Physiol 1993;75(2):856862.

77. Hoehn T, Krause MF. Effective elimination of carbon dioxide by nasopharyngeal high-frequency ventilation. Respir Med 2000;94(11):11321134.

78. Pillow JJ. High-frequency oscillatory ventilation: mechanisms of gas exchange and lung mechanics. Crit Care Med 2005;33(3 Suppl):S135S141.

79. Reyburn B, Li M, Metcalfe DB, Kroll NJ, Alvord J, Wint A, et al. Nasal ventilation alters mesenchymal cell turnover and improves alveolarization in preterm lambs. Am J Respir Crit Care Med 2008;178(4):407418.

80. van der Hoeven M, Brouwer E, Blanco CE. Nasal high frequency ventilation in neonates with moderate respiratory insufficiency. Arch Dis Child Fetal Neonatal Ed 1998;79(1):F61-F63.

81. Colaizy TT, Younis UM, Bell EF, Klein JM. Nasal high-frequency ventilation for premature infants. Acta Paediatr 2008 Nov;97(11): 1518-1522.

82. Dumas De La Roque E, Bertrand C, Tandonnet O, Rebola M, Roquand E, Renesme L, Elleau C. Nasal high frequency percussive ventilation versus nasal continuous positive airway pressure in transient tachypnea of the newborn: A pilot randomized controlled trial (NCT00556738). Pediatr Pulmonol 2010 [Epub ahead of print].

83. van Heerde M, van Genderingen HR, Leenhoven T, Roubik K, Plötz FB, Markhorst DG. Imposed work of breathing during high-frequency oscillatory ventilation: a bench study. Crit Care 2006;10(1):R23 .

84. Carlo WA. Should nasal high-frequency ventilation be used in preterm infants? Acta Paediatr 2008;97(11):1484-1485.

85. De Luca D, Carnielli VP, Conti G, Piastra M. Noninvasive high frequency oscillatory ventilation through nasal prongs: bench evaluation of efficacy and mechanics. Intensive Care Med 2010;36(12):2094-2100.

86. Versmold HT, Brünstler I, Schlosser R. In: Huch R, Duc G, Rooth G: Klinisches Management des kleinen Frühgeborenen $(<1500 \mathrm{~g})$. Stuttgart: Thieme; 1982:159-162. Book in German.

87. Pillow JJ, Hillman N, Moss TJ, Polglase G, Bold G, Beaumont C, Ikegami $\mathrm{M}$, Jobe $\mathrm{AH}$. Bubble continuous positive airway pressure enhances lung volume and gas exchange in preterm lambs. Am J Respir Crit Care Med 2007;176(1):63-69.

88. Lee KY, Dunn MS, Fenwick M, Shennan AT. A comparison of underwater bubble CPAP with ventilator derived CPAP in premature neonates ready for extubation. Biol Neonate 1998;73(2):69-75.

89. DiBlasi R, Poli J, Zignego JC, Barutcu B, Richardson CP. What are the effects of different bubble continuous positive airway pressure (b-cpap) systems on the magnitude of oscillations in lung volume while using a realistic airway/lung model of preterm infants? http://www.seattle childrens.org/doc/56th-AARC-intl-resp-congress-detail.doc. Accessed July 7, 2011.

90. Morley CJ, Lau R, De Paoli A, Davis PG. Nasal continuous positive airway pressure: does bubbling improve gas exchange? Arch Dis Child Fetal Neonatal Ed 2005;90(4):F343-F344.

91. DiBlasi RM, Zignego JC, Smith CV, Hansen TN, Richardson CP. Effective gas exchange in paralyzed juvenile rabbits using simple, inexpensive respiratory support devices. Pediatr Res 2010 [Epub ahead of print]

92. DiBlasi RM, Zignego JC, Tang DM, Hildebrandt J, Smith CV, Hansen TN, Richardson CP. Noninvasive respiratory support of juvenile rabbits by high-amplitude bubble continuous positive airway pressure. Pediatr Res 2010;67(6):624-629.

93. Sturtz WJ, Touch SM, Locke RG, Greenspan JS, Shaffer TH. Assessment of neonatal ventilation during high-frequency oscillatory ventilation. Pediatr Crit Care Med 2008;9(1):101-104. 


\section{Discussion}

Willson: Would you say more about the nasal cannula you invented? I think the interface is a big issue for NIV, not only in newborns but in our population as well, and we've not had anybody address that. It's fascinating to me that with just a small design change it looks like you're a lot more successful.

DiBlasi: The RAM nasal cannula [NeoTech Products, Valencia, California] was invented by Drs Heyman and Ramanathan. I was involved with some of the design work and research. It will be commercially available in October 2011. It differs from standard oxygen cannula and high-flow nasal cannula in having wider-bore tubing and soft silicone bi-nasal prongs that are similar in size to those used during nasal CPAP. The advantage is that more pressure can be transmitted to the lungs with this cannula during nasal IMV than with standard high-flow nasal cannula, and without the cumbersome fixation techniques that are often required with nasal CPAP prongs.

My concern with developing largerbore prongs for larger infants or small children is that they would have to be made quite large to transmit pressure to the child's airways, and therefore might not be light enough to interface as a "simple" nasal cannula and would probably require a cap or straps. I believe that folks have already begun working on such devices for toddlers and small children. I am also concerned by the resistance that may be imposed when higher $\mathrm{V}_{\mathrm{T}}$ and flow are applied with these interfaces as the patient gets larger.

Willson: Is it going to be available for older kids?

DiBlasi: To my knowledge these will only be available for neonates at this time.

Brown: I know you're primarily NICU, Rob, I think what Doug was getting at is that in the PICU [pediatric
ICU] it's bronchiolitis patients who are on that support. So it's not a stretch to think that something that's infant-sized would work for what they want to use it for.

DiBlasi: My research is focused on neonates, but I also work in the PICU and understand the need for noninvasive interfaces for larger infants and small pediatric patients. In the PICU I would use this new cannula on an 8-kg infant who was doing poorly on highflow or nasal CPAP to avoid intubation, for sure. Some folks are desperate and would use an adult nasal cannula, but I do not advocate that.

Wiswell: Rob, a worry with nasal cannula ventilation is the variability of intrathoracic pressure generated. In some trials in which they measured thoracic pressure there was an inverse relationship: the smaller the infant, the higher the intrathoracic pressure. A smaller premature baby—say, 750-900 g-may develop an intrathoracic pressure of $28 \mathrm{~cm} \mathrm{H}_{2} \mathrm{O}$ or more. This worries a lot of people, as we do not routinely measure intrathoracic pressure. I'm intrigued by the RAM cannula. NeoTech's medical director told me they're developing a nasal cannula that has a pressure-relief system once a pressure of $10 \mathrm{~cm} \mathrm{H}_{2} \mathrm{O}$ is generated. Are you familiar with that? High intrathoracic pressure worries me. Nasal cannula for ventilation is intriguing, but are we sure it's safe for babies?

DiBlasi: I don't know much about the high-flow nasal cannula situation, other than that its use is widespread across the United States. But that's a separate issue. In babies on nasal IMV, tracheal pressure measurements have indicated that $30-60 \%$ of the peak airway pressure is transmitted to the trachea. I would be more willing to use a nasal cannula to provide nasal IMV than high-flow therapy, because there is an exhalation valve regulating the pressure. We don't know what kind of intrathoracic pressure will be generated with a high-flow cannula system, because flow is monophasic and the delivered pressure is dependent on the patient leak. There is no pressure-relief valve in the RAM cannula, but I believe NeoTech is working on a separate cannula design, Adina, for high-flow therapy, which records proximal flow and limits pressure to around $10 \mathrm{~cm} \mathrm{H}_{2} \mathrm{O}$.

Wiswell: I look at the nasal IMV story as being similar to how people jumped on the bandwagon with high-frequency ventilation in the NICU. Similarly, there has been a widespread

increase in using nasal CPAP. Unfortunately, we have minimal supportive data on efficacy for all of these types of respiratory support. In the RCTs there has been minimal to no improvement in the major outcomes, including mortality,duration of ventilation, $\mathrm{BPD}$, and chronic lung disease. But despite the scant supportive data, many in neonatology are using these therapies in everyday practice. Neonatologists are "gizmo-olgists." We like playing around with new technology. This worries me. I see you had some of Robertson's pictures from the babies' nostrils, ${ }^{1}$ of damage we can see. New therapies may cause damage we are unaware of. Before jumping on the bandwagon we need to do good clinical trials and make sure therapies are safe and improve patient outcomes.

1. Robertson NJ, McCarthy LS, Hamilton PA, Moss AL. Nasal deformities resulting from flow driver continuous positive airway pressure. Arch Dis Child Fetal Neonatal Ed 1996;75(3):F209-F212.

\section{DiBlasi: Absolutely.}

Branson: This low-cost ventilator that you guys in Seattle have been working on is very interesting. A lot of us in academia have developed technology, but what happens when you need to manufacture it, and you have to get an ISO [International Organization for Standardization] facility to make the device, and then you need to meet FDA requirements for alarms and validation? For a company I'm aware of it took 7 years to 
get FDA approval for a bubble-CPAP system. With regard to this low-cost ventilator, essentially the engineers developed a Baby Bird. It's inexpensive, but it's 30 years behind current devices.

DiBlasi: The IMV device is separate from the high-amplitude bubble-CPAP device I showed you. Interestingly, these devices can be combined to provide the continuum of respiratory care to critically ill infants with respiratory failure. Nonetheless, the requirements and regulatory approach for any of these devices will be determined by stakeholders in the country where they'll be manufactured and used. We have involved neonatologists and pediatricians from all over India to provide feedback on the design of this ventilator. We're pursuing FDA approval, but this device may or may not be used in the United States. We are looking to use these devices where they do not have access to simple respiratory-support devices, so thousands of babies die every day. They have nothing. I saw this first-hand on a recent trip to India and Vietnam. The good news is that we have engaged stakeholders in India and we have begun discussing strategies for manufacturing these devices and conducting the necessary research in India.

Branson: What are the rules if you make it in the United States and ship it overseas?

Rogers:* The FDA does impose export regulations on mechanical respiratory devices. Unless the company is wholly outside the United States, there are a lot of export regulations to go through to get it out of the United States.

DiBlasi: Thanks Mark. That's interesting information because it conflicts a little bit with what we've been told in some of these countries. At this point our goal is to manufacture these devices

\footnotetext{
* Mark Rogers RRT, CareFusion San Diego, California.
}

in India, conduct the necessary clinical research, and then pursue FDA approval. Luckily, we have some donors who want to fund this project. Many of these types of projects fizzle out and never go anywhere.

Gentile: That's great, because neonatology is practiced differently in those countries. The device you showed might help. Another consideration is the ability to put other gases through the system, so it has multiple purposes. Regarding NAVA, this is great science, but it's interesting that you presented a bunch of studies in which they used the Infant Star ventilator. We'd all bring the Infant Star back, because the world didn't really know how good it was until it was gone. So far no studies have justified the cost of NAVA. I'm all for patient/ventilator synchrony and spontaneous breathing, but there's limited space in the esophagus, especially in tiny patients, for a nasogastric tube and the NAVA catheter.

DiBlasi: I think NAVA is a wonderful innovation and has a lot of potential, but I'm a little concerned because NAVA is invasive. Having placed many esophageal balloons in my time, I know that catheters can change position and the signal can be lost, so I've wondered if that happens during NAVA. Folks who use NAVA feel that, since you are placing an orogastric or nasogastric tube anyway, that negates the invasiveness of NAVA. But a standard nasogastric tube doesn't cost $\$ 500$ or $\$ 600$, so the cost of NAVA is a concern.

Is there going to be a large RCT with the 1,000-plus patients that would prove or disprove NAVA's clinical benefit? Who's going to fund that study? And will the benefits justify the cost of the software and catheters? So far, more papers have been published on NAVA than on pressure-regulated volume control in neonates, and that's a great start. I think 8 or 9 abstracts of NAVA studies have been submitted to the AARC [American Association for Respiratory Care] Open Forum this year.
Gentile: Esophageal balloon for PEEP and transpulmonary pressure measurement are becoming common in all patient populations, and these catheters are combined with a nasogastric, so one tube has multiple purposes. If we can get it outside the body, similar to a Graseby capsule, I think that's where we should be headed. Simply put the patient on a little PEEP and let them determine their own respiratory rate and $\mathrm{V}_{\mathrm{T}}$, unless they require more assistance.

Walsh: I struggle with the science, because I think we all know that NIV may be beneficial because you transfer more of the work of breathing to the patient. We tend to over-ventilate intubated patients, even though we think we're not. What would be the ideal clinical trial that would show whether bubble CPAP is better?

\section{DiBlasi: For our device?}

Walsh: Any noninvasive device: high-frequency, NAVA, et cetera. To me, intubation doesn't seem to be it.

DiBlasi: Several investigators have started that process, and some studies have been submitted to peer-reviewed journals. Trying to design the perfect study, especially in premature neonates, is very difficult, because the practice differs so much from one institution to the next. There are such disparities in practice, we don't know if we should be giving surfactant or supporting them with CPAP initially. If we can figure out how we're going to give the CPAP and surfactant, then we can go from there in designing trials with NIV.

Curley: In your bubble-CPAP device, why does angling the bubble tube in the water affect the oscillations?

DiBlasi: With small modifications in the distal tubing submerged in a simple CPAP water column, we developed a flow-interrupter device to increase the 
magnitude of high-frequency pressure oscillations delivered to the nasal airway of infants who would otherwise fail bubble nasal CPAP. By moving the bubbler angle from conventional bubble nasal CPAP ( 0 degrees) to 135 degrees in the water-column, we found that when a bubble breaks off, the airway pressure is at its lowest point; water rushes into the tubing and occludes it; gas flow is directed toward the nasal airway and pressure rises; gas then drives water out of the tubing, a bubble forms, and pressure decreases. These pressure oscillations produce enough energy to provide gas exchange similar to that from a conventional mechanical ventilator in paralyzed juvenile rabbits. ${ }^{1}$

This device, which we have termed high-amplitude bubble CPAP, has a lower bubbling frequency than conventional bubble nasal CPAP. The lower frequency provides more time for the airway pressure to equilibrate with the lung pressure, to displace a larger volume of gas. The frequency of conventional bubble CPAP is $10-20 \mathrm{~Hz}$ with an amplitude of $2 \mathrm{~cm} \mathrm{H}_{2} \mathrm{O}$. The pressure change with the bubbler at 135 degrees is around $8 \mathrm{~cm} \mathrm{H}_{2} \mathrm{O}$. So the angle changes the way that the water interacts with the gas, which reduces the frequency.

We studied this with high-speed video. We are able to allow the airway pressure to equilibrate with the lung or get closer to equilibrating, and that drives gas in and out of the lung. If you want me to go on about the complex interplay of the gases and the water, we can do that over a drink later.

1. DiBlasi RM, Zignego JC, Smith CV, Hansen TN, Richardson CP. Effective gas exchange in paralyzed juvenile rabbits using simple, inexpensive respiratory support devices. Pediatr Res 2010;68(6):526-530.

Curley: How are you going to evaluate the device in India? Have you asked the Gates Foundation for support in this? If anyone would be interested in improving outcomes in developing countries, it would be them.

DiBlasi: We are identifying manufacturers and potential research sites in India. The goal is to conduct multiple studies of the device over the next 5 years. We have submitted a grant proposal to the Gates Foundation, and others. You are correct: the Gates Foundation could have a huge impact in resource-limited settings.

Eiserman: ${ }^{\dagger}$ Regarding nasal cannulas, I would say "everything old is new again." We're looking at creative new uses for nasal cannulas that have a lot

$\dagger$ Jeri E Eiserman MBA RRT FAARC, Teleflex Medical, Research Triangle Park, North Carolina. of potential. We should be looking at the limitations and opportunities that are posed by an occlusive cannula such as Rob is talking about for infant nasal CPAP, versus a non-occlusive cannula, which is what's typically used in high-flow nasal cannula therapy.

We hear concerns from physicians using high-flow nasal cannula that they want to know the pressures created in the upper airways and the alveoli. I think one paper looked at oropharyngeal pressure in an adult at flows up to $40 \mathrm{~L} / \mathrm{min}$ and found very low oropharyngeal pressure, but perhaps enough to support the upper airways. We should determine what's really happening.

One of the disadvantages, from a research standpoint, of looking at something old in a new way is that we've been using nasal cannula therapy for so long that we think it's safe therapy. We're seeing evidence-mostly anecdotal - that high-flow nasal cannula is safe in most instances. Most of them have a pressure-relief valve, which is really getting at system pressure, because it's a high-back-pressure system, as opposed to what's necessarily going on in the baby's lungs. I think it's exciting to look at the use of nasal cannulas in the ways you've talked about, but it begs for additional research that takes a close and careful look at what we're doing with them.

This article is approved for Continuing Respiratory Care Education credit. For information and to obtain your CRCE

(free to AARC members) visit

www.RCJournal.com

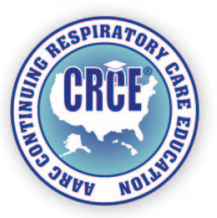

